\title{
Valuing the water supply: ecosystem-based potable water supply management for the Legedadie-Dire catchments, Central Ethiopia
}

Yilikal Anteneh $^{1 *}$, Gete Zeleke ${ }^{1}$ and Ephrem Gebremariam ${ }^{2}$

\begin{abstract}
Background: There is a substantial interest in the values that consumers place on drinking water quality and supply. Financial resources are crucial to improving the urban potable water supply in developing countries that are characterized by low-cost recovery rates and a high and rapidly growing demand for more reliable services. This study examined households' willingness to pay (WTP) for the improvement of water services by identifying their water choice decisions and the mode of water supply that they prefer the water supply authority to use among several alternative water supply options. Stated-preference data were collected from 322 randomly selected households in Addis Ababa, who were presented with three sets of choices (three alternative bundle choices, including the reference scenario). The data were analyzed using the mixed logit WTP space model. Three approaches to modeling the distribution of WTP (fixed, uncorrelated, and correlated) using mixed logit WTP space models were compared.
\end{abstract}

Results: Three-quarters of the households agreed to contribute money toward ecosystem-based water supply management (EBWSM) intervention programs on a monthly basis. The average contribution that the respondents were willing to pay was 150.5 Ethiopian Birr (ETB) as a one-off lump sum to kick off the EBWSM activities. Most of the respondents chose a bundle of water supply options that provides risk-free and high-quality water with no months of shortages than moderate water quality that is safe to drink and palatable with 1 month shortages annually. This implies that households would need to be supplied with risk-free, high-quality water without interruption at an appropriate flow pressure. The model with correlations fitted the data well with the highest simulated log-likelihoods at convergence and gave the best estimate of the households' WTP for water improvement. Nearly $46 \%$ of the sampled households were willing to pay more than 33 ETB per month, and $49 \%$ of the households were willing to pay between 21 ETB and 33 ETB per month for the monthly water bill. Overall, approximately 95\% of the sampled households were willing to pay more than 21 ETB.

Conclusion: Customers are willing to pay to avoid most types of water supply restrictions. Moreover, WTP is sensitive to the scope of service improvement, income, affixed price, and elicitation method. In summary, mixed logit WTP-space models can help accurately predict household-level WTP, which can be used to select improvements in drinking water access and services in the Legedadie-Dire catchments.

Keywords: Ecosystem service, Water supply, Mixed logit, WTP-space model, Catchment management, Legedadie reservoir

\footnotetext{
* Correspondence: yiliku100@live.com

${ }^{1}$ Water and Land Resource Center (WLRC), Addis Ababa University, 3880

Addis Ababa, Ethiopia

Full list of author information is available at the end of the article
} 


\section{Introduction}

Urban drinking water is publicly supplied under regulation. Globally, nine of every ten people do not have their wastewater treated to any degree, five of ten have inadequate sanitation, and two of ten lack access to a safe water supply (World Bank 1996). In most parts of Ethiopia, the low public investment and insufficient tariffs in urban water supply systems have resulted in low levels of service, rationing, and unscheduled disruptions (World Bank 1996). Running the existing water supply system in Ethiopia is constrained by an enormous financial gap, which creates a burden for the government (Brixi 2009; Butterworth et al. 2013; Ludi et al. 2013). For example, the government covers nearly $44 \%$ of the financial costs of the entire water supply program in the country, and the remaining $56 \%$ is covered by external support agencies (Tarfasa 2013). Nevertheless, financing the water supply system is imperative to diversify livelihood options for the urban poor in addition to ensuring their access to water because the lack of water supply, hygiene, and sanitation takes an enormous toll on health and well-being and has a large financial cost, including a sizable loss of economic activity (Connor 2015). Limited access to water is a particularly large burden to women's economic empowerment because women in many countries continue to carry the full burden of water inequality. Studies show that women bear the primary responsibility for water collection. Time lost due to walking and waiting for water has a ripple effect on their lives, their communities, and the entire economy. This time cannot be spent carrying out income-generating activities to diversify their livelihoods, which could contribute to poverty alleviation and social and economic development (WWAP 2015; Connor 2015). Thus, ensuring an improved water supply system is key to promoting their livelihoods and broadening the diversification options.

Generally, two approaches can be used to measure the economic value of the quality and availability of nonmarket commodities: revealed preference and stated preference approaches (Vuletić et al. 2009; Freeman III et al. 2014). In the revealed preference method, the values of nonmarket environmental goods and services are inferred from other market transactions; these methods include aversion cost, travel cost, and hedonic pricing (Pearce 2002; Adamowicz et al. 1994). The stated preference method is based on hypothetical questions that allow individuals to report their willingness to pay (WTP) for the intended service or value (Adamowicz et al. 1994). This method includes common variants such as the contingent valuation and discrete choice experiment (DCE) approaches (Mogas et al. 2006). Both contingent valuation and DCE approaches present respondents with a survey of questions to assess whether they are willing to pay for modifications to features of the product in question. The survey gives respondents a list of alternative scenarios characterized by several attributes (Adamowicz et al. 1998).

Although contingent valuation is the most frequently employed valuation tool in environmental economics (Bateman et al. 2003), it is often criticized as being inadequate to value a single attribute of multiattribute nonmarket goods and services (Louviere et al. 2000; Bateman et al. 2003). In contrast, the DCE approach enables the investigation of an attribute of a product and model in an individual or a household's decision-making process in a hypothetical situation (Louviere et al. 2000), which makes it an appropriate alternative tool. DCE is a survey-based methodology for modeling preferences for goods that can be described based on their attributes and levels. Several alternative descriptions of a good, which are differentiated by their attributes and levels, are presented to respondents, who rank or rate their preferred choices. By using price an attribute of a good, WTP can be indirectly recovered from the respondents' rankings, ratings, or choices. Like contingent valuation, DCE can estimate all forms of value, including nonuse values. Its conceptual microeconomic framework lies in the characteristics theory of value of Lancaster (1966), which assumes that consumers' utilities for goods can be decomposed into utilities for their characteristics. DCE has been applied in environmental science more recently than in market-based and transport-related research, where it has been widely used. As recommended by Carson and Louviere (2010), the term "discrete choice experiment" is used throughout this article to avoid confusion because the expression "choice experiment" has different connotations in other disciplines, such as physics and biology.

\section{Payment for ecosystem services}

Payment for ecosystem services (PES) schemes are designed so that buyers purchase-more or less explicitly-services from providers (Rowcroft et al. 2011). PES schemes may be a compliment or a substitute for regulations under which land and water operators must observe certain levels of ecosystem provisions (DEFRA 2013). The payments represent an explicit economic encouragement to land managers to deliver ecosystem services (ESs) via market-like incentives (Thomson et al. 2014) because there are direct influences on the provision of many ESs, of which land managers are often not aware (Bonn et al. 2009). For example, water quality has deteriorated due to the application of modern agricultural inputs, such as pesticides and fertilizers. Moreover, land managers are often unfamiliar with the impacts of their actions on downstream users and third parties, such as downstream water users (Molle 2004). 
These so-called externalities can be positive or negative. Market prices have typically overlooked and ignored such environmental externalities (Chander and Tulkens 2006). Even if the impacts of upstream activities on ESs are clearly understood by land operators, including these services into their management activities is not in their economic interest because they provide them no additional benefit (Chander and Tulkens 2006). A PES scheme for a watershed includes various stakeholders, such as landowners (upstream and downstream), farmers (which may be landowners but also potential polluters), local and distant domestic consumers, enterprises that require clean water (e.g., distilleries, food, water processors), and fishermen as well as residents and state governments and agencies.

One way to address land managers' externalities is via mechanisms that integrate the externalities into transactions systems of PES schemes (Van Bueren and Bennett, 2004). Land managers are rewarded (usually through cash payments) by resource users for providing ESs under PES schemes, thereby internalizing the externalities (Engel et al. 2008). Service beneficiaries, such as urban dwellers, who obtain their potable water from an upstream catchment should have to reward service providers, such as upstream farmers, as land managers, which is the basic principle behind ecosystem service providers. These rewards are manifested by incentivizing farmers for their efforts in supplying these services in a sustainable fashion to the benefit of buyers, sellers, and nature itself. This approach is expected to have multiple advantages because it values many nature services that are commonly taken for granted while simultaneously raising awareness of service existence and human impacts and highlighting the social interdependence of providers and buyers.

\section{The context of drinking water supply in developing countries}

It is commonly accepted that sustaining human life and ensuring good health and human dignity are directly associated with the provision of potable water, sanitation, and hygiene (Akinyemi et al. 2018). This encourages the formation of a more reasonable, productive, and healthier community structure. Water quality continues to be the concern of many developing countries despite the steady improvement in drinking water supply throughout the world (Watkins 2006).

Clean and safe drinking water is one of the most important necessities of life. Currently, water scarcity affects more than $40 \%$ of people around the world, and by 2030 , the global demand for water is expected to increase by $50 \%$ (Habitat, U.N 2016). According to Bryce et al. (2005), approximately 844 million people globally lack access to a supply of potable water, and approximately 2.5 billion people have no access to adequate sanitation. Today, many developing countries face serious problems related to water. Evidence abounds that public water supplies in rural and semi-urban centers in developing countries, such as in Africa, are generally inadequate and unreliable compared with the rate of population growth (Jideonwo 2014; Coster and Otufale 2014; Ben and Ogunyemi Omotayo 2015).

Khan et al. (2006) estimated that in 2000, Africa had $28 \%$ of the world's population without access to clean water. It was also estimated that 319 million people in sub-Saharan Africa (equivalent to $51 \%$ of the population) lack access to a supply of safe water and that $41 \%$ lacks adequate sanitation. The others obtain water from sources such as wells, boreholes, and streams, which may not be clean. Scarcity of drinking water causes higher rates of sickness and death and leads to higher health costs, low work productivity, lower school enrollment, and ultimately poverty (Ahmad and Sattar 2010).

Challenges in the water sector are also challenges for the food production sector and thus are obstacles to meeting other societal necessities and goals. For example, approximately $70 \%$ of water use is accounted for by the agricultural sector (Alcamo et al. 2017), which supports the livelihoods of large numbers of households worldwide. Therefore, in their attempts to design and apply effective strategies, poverty assessment researchers have identified water as the critical element and have consistently proposed improvements in water supply services as a working approach for poverty reduction. The challenge is even more severe in Africa, where water stress is already evident in approximately 14 countries, and an additional 11 countries are expected to experience water stress by 2025 . This will cause nearly half of Africa's population to face water stress or scarcity by 2025 (Hoekstra et al. 2012). Reducing the population that lacks access to adequate water and basic sanitation by half, which is enshrined in the millennium development goals (MDGs), would help to ensure the availability and sustainable management of water and sanitation for all.

Ethiopia is one of the sub-Saharan African countries that has a discrepancy between the demand for and supply of improved drinking water (Soto Montes de Oca and Bateman 2006). Approximately $43 \%$ of the population does not have access to an improved water source, and $28 \%$ practice open defecation. In addition, the prevailing very low and insufficient income and subsidies given to the expansion and maintenance of water facilities and infrastructure that are necessary to ensure an improved water supply (Gadgil 1998) have had a significant impact on health. Approximately 60 to $80 \%$ of communicable diseases are attributed to the limited access to safe water and inadequate sanitation and hygiene services (Tessema 2017). An estimated 22\% of children under five die because of diarrhea (the third leading 
cause of under-five mortality), which is attributed to poor water, sanitation, and hygiene. Diarrhea prevalence is highest among children residing in households that drink from exposed wells (18\%) and those residing in rural areas (14\%). Nearly $50 \%$ of the consequences of undernutrition are caused by environmental factors that include poor hygiene and a lack of access to water supply and sanitation (Tessema 2017). Moreover, the majority of health facilities in Ethiopia lack access to clean water, and only approximately $32 \%$ have access to safe water (Welle et al. 2012).

Generally, evidence suggests that people's health and living conditions can be improved by preventing the spread of fatal diseases through improved water access (Akinyemi et al. 2018). Therefore, working toward improved water access substantially helps to address the challenges of poverty, hunger, health, and inequality in an integrated approach (WaterAid 2017). Such an approach incorporates the productivity and survival of human life and agro-ecosystems into its key services for people (Dessalegn and Merrey 2015). In this regard, the limited financing of this sector remains a bottleneck to addressing the challenges of improved water supply given its capital-intensive nature. One factor that has contributed to the water sector's financial problems is the increase in the volume of unaccounted water; treated water is not accounted for since its precise destination is not known. It is estimated that approximately $36.5 \%$ of the average daily production of water in Addis Ababa is unaccounted for because of leaks, metering inaccuracies, bursts of old pipes, theft, or illegal connections. Moreover, tariff levels remain below the cost recovery levels. The low tariffs and inadequate government investments make it difficult to supply improved water. The prevailing large water supply deficit and poor water quality signals the presence of high demand for improved water supply service; hence, it is likely that most residents would be willing to pay more for the service once it has been improved.

\section{Water supply issues in Addis Ababa}

The city of Addis Ababa is located downstream of the Legedadie-Dire catchments, which are part of the Akaki River Basin (Ebba 2006). The city has been divided into ten subcities for administrative purposes by the city government (Fig. 1) and has been further segmented into eight water distribution branches of authority (Fig. 2) by the Addis Ababa Water and Sewerage Authority (AAWSA). Water users are distributed over these eight water supply branches in the cities. Thus, residents of a particular sub-city can be supplied with water from different distribution branches even though they are within the same administrative sub-city.

Previous studies have shown that land use and land cover change (LULCC) over the past several decades
(Anteneh et al. 2018a), combined with improper utilization and poor natural resource management of the land, rivers, vegetation, and the ecosystem at the catchment level, have led to sedimentation and siltation of the Legedadie and Dire reservoirs (Gebresamuel et al. 2010; Anteneh et al. 2018b). This has accelerated the deterioration of the reservoir water quality and quantity (Kebede and Kebedee 2012). Silt deposits (Andualem and Yonas 2008), algal blooming (Mesfin and Belay 1989; AAWSA 1994), heavy metals such as lead (Tamene 2008), pathogens (Mesfin and Belay 1989), and other pollutants have significantly affected both the quality and quantity of the reservoir water. Crampton and Ragusa (2008) indicated that water contamination in Addis Ababa has low levels of risk but a very high frequency of infection. In a study of how clean drinking water at the water source can be contaminated before human consumption, Crampton and Ragusa (2008) noted that of the 127 water samples collected, 34\% were contaminated with fecal bacteria, $33 \%$ of water sources were contaminated $(n=72)$, and $37 \%$ of the point-of-use water samples contained fecal bacteria $(n=54)$. Although $34 \%$ of samples tested positive for some level of contamination, $52 \%$ of these scores were at a level that would present low risks to human consumers.

The live storage capacity of the Legedadie reservoir decreased by 2.1 million cubic meters $\left(\mathrm{Mm}^{3}\right)$ from 1979 to 1998 with an annual sediment load of $110,000 \mathrm{~m}^{3}$, and it deceased by $1.62 \mathrm{Mm}^{3}$ from 1998 to 2010 with an annual sediment load of $135,000 \mathrm{~m}^{3}$ (MPR 2011). This situation has had a substantial impact on the quality, quantity, pressure, and distribution of the water supply. Currently, the demand for water in Addis Ababa exceeds the supply, and the demand for potable water is growing nearly three times faster than the water supply. The total potable water demand of the city increased from $206,230 \mathrm{~m}^{3}$ per day in 1994 to $326,137 \mathrm{~m}^{3}$ per day in 2002 (AAWSA 2004), 380,000 $\mathrm{m}^{3}$ per day in 2004 (Sime 1998), and $616,108 \mathrm{~m}^{3}$ in 2011 (AAWSA 2004), and it is projected to reach $1,105,000 \mathrm{~m}^{3}$ per day in 2020 and $1,329,585 \mathrm{~m}^{3}$ in 2025 (Sime 1998; AAWSA 2004). The total annual water production of the city also increased from $55 \mathrm{Mm}^{3}$ in 1992 to $64 \mathrm{Mm}^{3}$ in $1998,80 \mathrm{Mm}^{3}$ in 2004, $92.2 \mathrm{Mm}^{3}$ in 2008, and approximately $109.5 \mathrm{Mm}^{3}$ in 2011 (Bereket 2006).

Most studies in Ethiopia have reported water pressure in meters of water column $\left(\mathrm{mH}_{2} \mathrm{O}\right)$, where 1 pounds per square inch (PSI) is equal to $0.70307 \mathrm{mH}_{2} \mathrm{O}$. Customers often complain that the water pressure is very low in most parts of the city (Gamtessa 2008). Reports of the water supply pressure in Addis Ababa are varied. The Addis Ababa water supply has been reported to be 45 PSI (TAHAL, SMEC, WWDSE, HyWAS 2005), 34 PSI (Liemberger et al. 2007), and 36 PSI (Mengistu and 


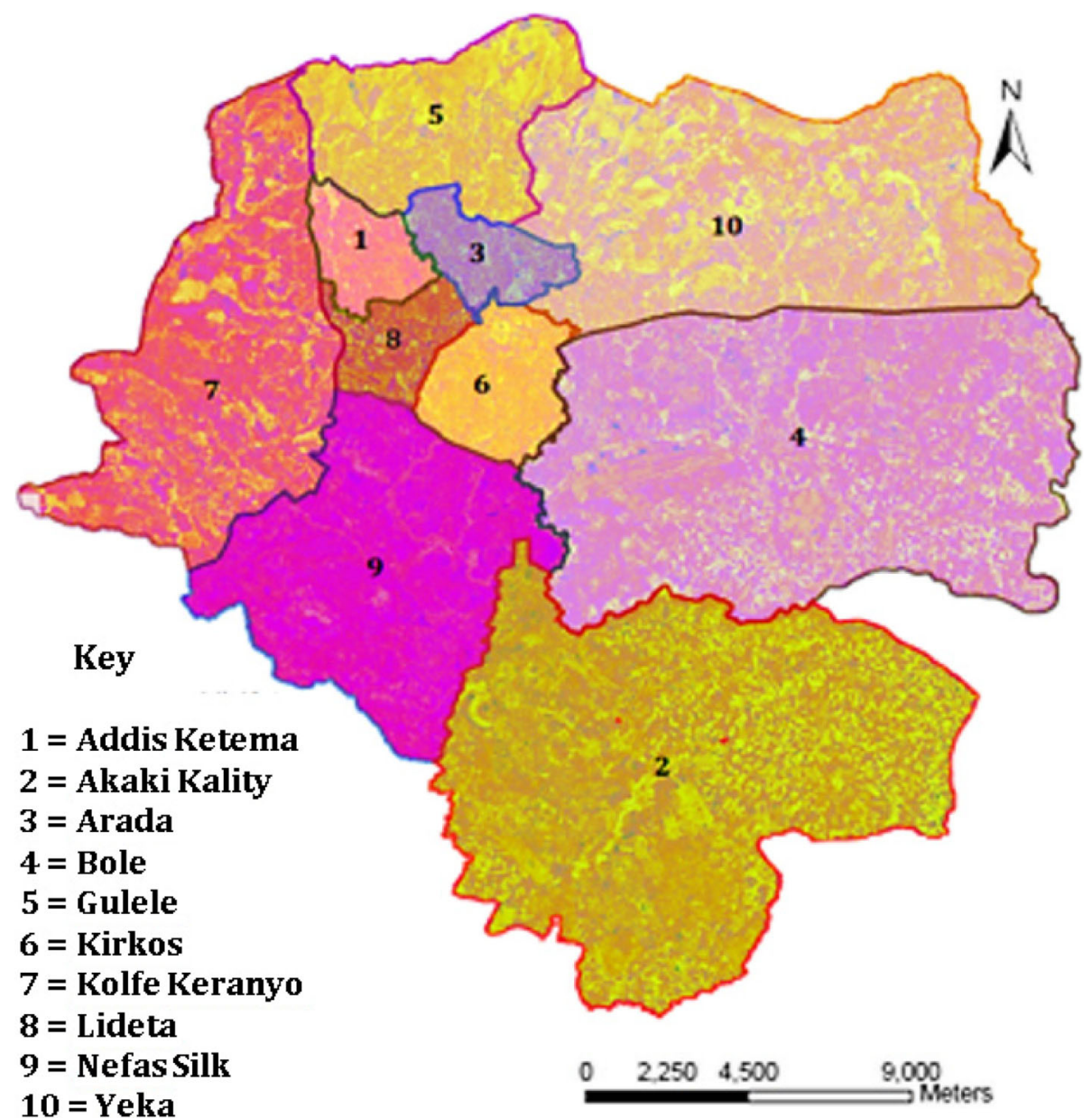

Fig. 1 Map of the ten subcities in Addis Ababa

Savage 2010). According to Twort et al. (1994), the domestic water pressure for residential purposes tends to range from 45 to $80 \mathrm{PSI}$. A water pressure below $40 \mathrm{PSI}$ is considered to be low, and a pressure below 30 PSI is considered to be too low (Twort et al. 1994). A pressure above 80 PSI is too high (Twort et al. 1994). Low water pressure is more of a nuisance and contributes to water scarcity, although some equipment has minimum requirements, such as washing machines. In contrast, high water pressure significantly increases the risk of damage to pipes, joints, and fixtures and increases water waste (Witzke et al. 2012). For example, urban supply pressures in the UK are $4-5$ bar (60-70 PSI), and the minimum pressure is 40 PSI in Idaho, USA (Colby et al. 1989).

The mean daily per capita domestic water demand in liters is estimated to have been $61 \mathrm{l} / \mathrm{c} /$ day in 2011, $83 \mathrm{l} /$ c/day in 2015, and $95 \mathrm{l} / \mathrm{c} /$ day in 2017 and is projected to be $105 \mathrm{l} / \mathrm{c} /$ day in 2019 and $110 \mathrm{l} / \mathrm{c} /$ day by the end of 2020, which represents an annual increase of $6.6 \%$ (AAWSA 2011). Based on the AAWSA's records, the total billed volume of water in 2010 was approximately
$62.35 \mathrm{Mm}^{3}$, of which approximately $50.4 \%$ was for domestic consumption, $48 \%$ was for nondomestic use, and $1.7 \%$ was for public tap users. The total annual water demand for Addis Ababa is estimated to reach $252 \mathrm{Mm}^{3}$ by 2020 , of which an average $68 \%$ is the domestic water demand, and $32 \%$ is for nondomestic demand.

Generally, the value of drinking water does not depend solely on its quantity, quality, and pressure but also on several other factors, such as location or distance from the source, travel time and time of availability, the taste of the water, and the reliability of access. Improved water supply service management requires decisions based on social equity, economic efficiency, and ecological sustainability. Thus, this study is important for water supply service management and pricing options for users across the subcities with reference to the estimated WTP results. Moreover, attaching a monetary metric to water services is helpful for planners, policy-makers, and decision-makers to make appropriate decisions regarding development and better allocation of urban drinking water supply service. 


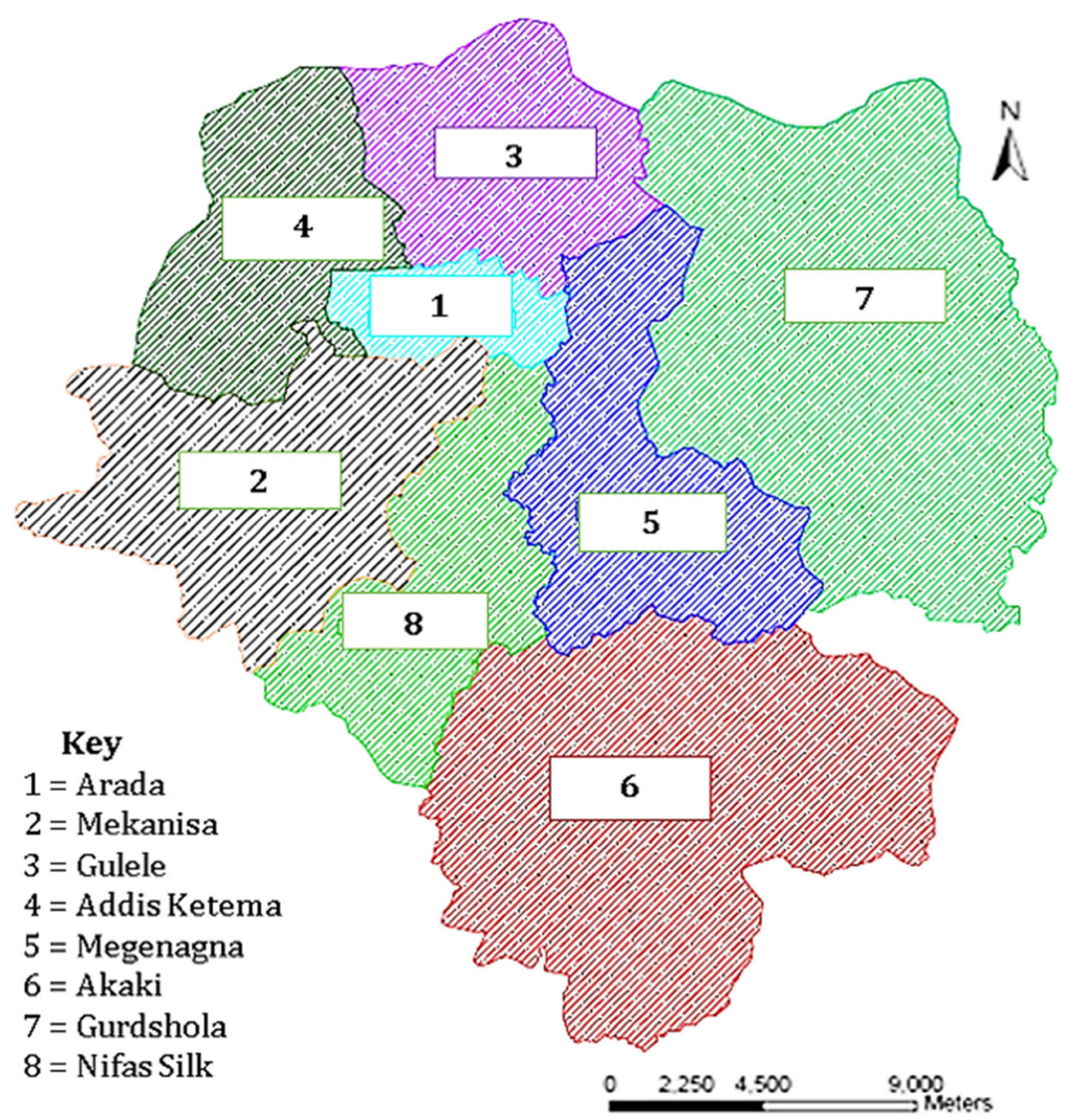

Fig. 2 AAWSA water distribution branch offices in the city, which do not follow the sub-city boundaries

\section{Methodology}

\section{Survey design of the discrete choice experiments}

We assumed that the current drinking water supply requires improvement to satisfy the needs of the customers. In considering how individuals make choices about the water supply as a good, Lancaster (1966) noted that the supplied water characteristics give rise to consumer satisfaction. Water supply usually exhibits multiple characteristics (e.g., quality, quantity, pressure), and many water supply approaches use individual characteristics. In addition, a combination of various water supply approaches will give rise to features that are not present when each water supply characteristic is examined separately. This approach indicates that to understand consumers' water supply choices, researchers must understand how consumers value the specific characteristics of the water supply separately as well as in combination (Lancaster 1966).

The first step in designing a choice discrete experiment is to identify the ecosystem-based water supply management (EBWSM) choice attributes and define their levels (Table 1). The attributes should have policy implications and be related to the suggested interventions and expected outcomes. Hence, they should be relevant to the policymaking process. Supply and demand-driven approaches have been considered in determining and developing the choice attributes and levels (Sangkapitux et al. 2009). The supply-driven approach has been used in studies of the city's water supply and impoundment (Elala 2011; Taye et al. 2013; Andualem and Yonas 2008; Bereket 2006; Mengesha 2014), catchment rehabilitation and ES management (AAWSA 2011), and prevailing land change and resources degradation in the catchments (Taye et al. 2013).

Moreover, to help in the process of the DCE design, a pilot survey was conducted on 53 sample households in the Akaki subcity as a demand-driven approach. The main objective of the pilot survey was to understand the resident's perspectives towards the existing water supply system and to incorporate the data into the design of the EBWSM choice attributes and levels. Three EBWSM attributes were identified, and their levels were used in the DCE design (Table 1). 
Table 1 Attributes and levels used in the DCEs to improve EBWSM

\begin{tabular}{|c|c|c|c|c|}
\hline No & Attributes & Description & $\begin{array}{l}\text { Current status/status } \\
\text { quo }\end{array}$ & Attribute levels \\
\hline \multirow[t]{2}{*}{1} & \multirow[t]{2}{*}{ Water quality } & \multirow{2}{*}{$\begin{array}{l}\text { Improvement of the quality of municipal drinking water from the source } \\
\text { via upstream EBWSM interventions (reinstate riparian ecological conditions } \\
\text { via buffering along rivers and reservoirs, application of conservation } \\
\text { agriculture with controlled grazing, grass filter strips, and reforestation } \\
\text { activities on degraded lands) in the Dire-Legedadie catchments. This can } \\
\text { improve not only the surface water supply (such as water stored in the } \\
\text { reservoirs) but also augment the potential of the upstream catchment in } \\
\text { recharging groundwater sources (Akaki wellfields). }\end{array}$} & \multirow[t]{2}{*}{$\begin{array}{l}\text { High risk of } \\
\text { contamination }\end{array}$} & $\begin{array}{l}\text { Risk-free and high-quality } \\
\text { water }\end{array}$ \\
\hline & & & & $\begin{array}{l}\text { Moderate water quality yet } \\
\text { palatable and safe to drink }\end{array}$ \\
\hline \multirow[t]{2}{*}{2} & \multirow[t]{2}{*}{ Water quantity } & \multirow[b]{2}{*}{$\begin{array}{l}\text { Application of upstream catchment EBWSM interventions (afforestation } \\
\text { and reinstate riparian ecological conditions via buffering along rivers and } \\
\text { reservoirs) that can initiate continuous water flow to reservoirs by } \\
\text { reducing sedimentation and improving the storage capacity of the } \\
\text { reservoirs in the Dire-Legedadie catchments. This will increase the drinking } \\
\text { water supply. Such interventions can improve the surface water supply } \\
\text { (such as water stored in the reservoirs) and also augment the potential of } \\
\text { the upstream catchment in recharging groundwater sources (Akaki } \\
\text { wellfields). }\end{array}$} & \multirow{2}{*}{$\begin{array}{l}2-3 \text { months of } \\
\text { shortages annually } \\
\text { (1 week-10 days/ } \\
\text { month) }\end{array}$} & No months of shortages \\
\hline & & & & $\begin{array}{l}1 \text { month of shortages } \\
\text { annually } \\
(2-3 \text { days/month) }\end{array}$ \\
\hline \multirow[t]{2}{*}{3} & Water pressure & $\begin{array}{l}\text { Management of water distribution systems and improvement of flow } \\
\text { pressure by installing leak detection and pressure control equipment and } \\
\text { other water distribution facilities that can conserve unnecessary drinking } \\
\text { water leakage and unaccounted water losses. }\end{array}$ & $\begin{array}{l}\text { Unpredicted and low } \\
\text { pressure in most } \\
\text { areas }\end{array}$ & $\begin{array}{l}\text { Normal pressure ( } 40 \text { to } 55 \\
\text { PSI) }\end{array}$ \\
\hline & $\begin{array}{l}\text { Compensation } \\
\text { payment }\end{array}$ & $\begin{array}{l}\text { Households' WTP for an improved municipal water supply per month in } \\
\text { addition to the monthly water bill. }\end{array}$ & No payment & $\begin{array}{l}\text { 12.50, } 18,21,25,29 \text {, and } \\
36 \text { ETB per month }\end{array}$ \\
\hline
\end{tabular}

Water supply alternatives are based on various combinations of specific water supply attributes, including the water quality, water quantity, water pressure, and alternative price options. Various water supply studies have included four to six alternative price options (Mulatu 2013; Tanellari et al. 2015; Um et al. 2002; Casey et al. 2006; Genius et al. 2008; Vásquez et al. 2009). Considering the socioeconomic characteristics of the respondents as well as the previous studies, we presented six alternative price options in this study. Each payment choice depends on the chosen alternatives and is to be paid by households with their monthly water bills, including 12.50 ETB month $^{-1}, 18$ ETB month $^{-1}, 21 \mathrm{ETB}^{-1}$ month $^{-1}$, $25 \mathrm{ETB}_{\text {month }^{-1}}, 29 \mathrm{ETB}^{\text {month }}{ }^{-1}$, and $36 \mathrm{ETB}^{-1}$ month $^{-1}$ (where $1 \mathrm{ETB} \approx 0.0494$ United States dollars; USD). To provide flexibility for the households, we use diverse rather than fixed ranges between each price option from 3 to 7 ETB.

Choice 1 includes a bundle of water supply options that provides moderate water quality that is safe to drink and palatable with one month shortage annually (2 -3 days month $^{-1}$ ) and normal water pressure (40 to 55 PSI).

Choice 2 contains a bundle of options that provides risk-free and high-quality water with no months of shortages annually and normal pressure (40 to $55 \mathrm{PSI}$ ).

Choice 3 (i.e., the reference scenario or status quo option) includes water quality with a high risk of contamination, two to three months shortages annually (i.e., 1 week to 10 days month $^{-1}$ ) with unpredicted (i.e., extremely low or extremely high) pressure as per the 2011 AAWSA business plan.

The WTP elicitation questions were formulated to determine whether the respondents would be willing to pay a certain amount per year with their monthly bills in support of water supply improvement efforts (Table 2). The questions must be administered prior to the DCE survey; hence, if the household were not willing to participate in the EBWSM, he/she would be given the protest followup questions instead of the subsequent DCE alternatives. The survey design also included questions to generate information about the sociodemographic characteristics and the existing water demand and supply situation as well as the overall purchasing behavior and attitudes toward the drinking water supply of the households.

\section{The experimental design process}

The core of the stated preference technique is statistically characterized by the design of games with hypothetical alternatives to be presented to respondents. Orthogonal design is one of the most commonly applied experimental designs. Orthogonality refers to the correlation structure of the design attributes, where designs with zero correlations are said to be orthogonal; in other words, this guarantees that respondents will be exposed to attributes that vary independently from one another (Sanko 2001). Under this definition, each attribute of the design will be independent of all other attributes, 
Table 2 A sample elicitation

Section 3-Elicit willingness-to-pay values: DCE scenario presented to the downstream community members as a valuation scenario for Ecosystem-Based Water Supply Management (EBWSM) in the DireLegedadie reservoirs. (Note to the Interviewer: read the following introduction to the respondents very clearly.)

You have been randomly chosen from the residents of Addis Ababa to be involved in this survey. There is a large gap between the supply and demand for potable water in Addis Ababa in addition to the high risk of water contamination. This is mainly attributed to the increasing population growth rate in the city, natural resource degradation across the upstream catchments, which is leading to siltation in the reservoirs, and the poorly managed pipelines and water distribution systems, which is demonstrated by leakage and loses. The provision of improved water service requires proper management of both the water source and supply systems. We want to explore the residents' preferences for EBWSM interventions to improve the ecosystem health of the upstream catchments (Dire-Legedadie reservoir catchments) to increase the quality and quantity of drinking water supplied to the city. Please consider the following two EBWSM interventions.

Improvement of water quality status supplied by the municipality: The raw water quality in the Dire-Legedadie reservoirs has deteriorated over the past several years (greater than 1600 Formazin Turbidity Units; FTU) due to transportation, deposition, and building up of silt, suspended solids, pathogens, and chemicals such as pesticides, chemical fertilizers, and other pollutants from the upstream catchment to the reservoirs.

This will cause degraded raw water quality and will significantly increase the cost of raw water treatment. The effectiveness of water treatment becomes burdensome due to increased costs and makes the drinking water unsafe and risky. However, the raw water quality can be improved through appropriate upstream catchment management alternatives, which can reduce costs and make further water treatment more effective. Appropriate upstream catchment management alternatives may include reinstatement of riparian ecological conditions by establishing buffers along rivers and reservoirs, the application of conservation agriculture with controlled grazing, managing waterways through grass filter strips and reforestation activities on degraded lands. Enhancing water quality through upstream catchment management alternatives will also reduce the burden on the municipality with regard to water quality treatment. And it provides an opportunity to focus on the distribution management systems (e.g., regulate and control the distribution system, maintain and replace old and leaky pipelines) and thus reduce the risk of water contamination, which will make the drinking water risk-free and have a high quality.

Enhancement of water quantity and pressure to be supplied by the municipality: Sedimentation and siltation in the Legedadie reservoir have consistently reduced the live storage capacity of the reservoir, which influences the water quantity. Nevertheless, upstream catchment management can be performed through EBWSM interventions (afforestation and reinstating riparian ecological conditions via buffering along streams and reservoirs). These interventions will increase the drinking water supply for the city by means of decreasing the siltation rates and increasing the reservoir's storage capacity. Moreover, upstream catchment management can increase the effectiveness of water recharge and infiltration, which improves the capacity of the groundwater reserves in the Akaki wellfields. This will in turn help to ensure the sustainability of the water supply systems in Addis Ababa. In addition, managing the distribution systems will help to prevent the unnecessary wastage of drinking water through leakage. Therefore, the existing disparity between the water supply and demand can be improved significantly, and water would be available in your house without shortages and at a higher pressure for drinking, showering, washing dishes, and doing laundry at the same time. However, such changes in water improvement will incur additional costs for the execution of the management alternatives that focus on upstream water supply enhancement, which are costly to implement by the municipality or water agency alone. Rather, such programs would be effective if adequate funds are produced through a contribution by the community. Hence, for such an improved water supply scheme, you
Table 2 A sample elicitation (Continued)

would be required to pay a certain amount of money with your monthly water bills. To determine your WTP for these interventions, a monetary value for the improved water supply (i.e., drinking water quality and quantity) in Ethiopian ETB per month is also included in the choices.

Are you willing to pay a certain amount toward the EBWSM interventions? 1. Yes, 2. No (if No, proceed to Q. 62)

Would you participate and go to meetings and workshops to discuss your views on the EBWSM options?

1. Yes, I would be very interested and would attend meetings and workshops to discuss the EBWSM options.

2. No, I would not attend meetings and workshops to discuss the EBWSM options because I do not have time to do so.

3. No, I do not think we need a new water supply system. I am happy with my current water supply situation.

4. No, I would not attend meetings and workshops because I do not believe that an improved system will be built.

5. No, I would not attend meetings and workshops because it is the responsibility of the government to provide water for free.

6. Other

reasons

although some orthogonal designs assume orthogonality only for attributes within alternatives but not between them. The result is that the effect of each attribute level on the responses is more easily isolated. This avoids "multicollinearity" between attributes, which is a common problem with revealed preference data (Sanko 2001). Details of the CE that we used are described elsewhere, and we provide only a brief overview. The attributes and attribute levels (Table 1) were based on a review of the literature (Xiong et al. 2018), initiatives of new local water improvement plans (AAWSA 1994; AAWSA 2004; AAWSA 2011), and expert opinions.

The experimental design presented in this study is a full factorial design that uses every possible combination of attribute levels. The number of combinations is the result of the number of levels raised to the power of the number of attributes. The raised values are simply multiplied when attributes with different numbers of levels are included (Sanko 2001). Thus, the combination of all attributes and levels results in a full factorial experimental design, which gives $2^{2 *} 1^{1 *} 6^{1}=24$ different EBWSM alternatives (a design with 2 two-level attributes, 1 one-level attribute, and 1 six-level attribute would have 24 scenarios).

Thus, an orthogonal full factorial design with 24 scenarios with 8 choice sets was created. For a meaningful study, it is usually not possible to administer such a large number of choice sets (Hanley et al. 2006; Lusk and Norwood 2005). Hence, the choice sets or games are randomly assigned to two groups. Each respondent was given four choice sets with three alternatives in each choice set, including the status quo option. The survey 
started with a short introduction of the purpose and a description of the attributes, their levels, the choice tasks, and follow-up questions. Three statistical software packages were used in this study. The JMP statistical software (SAS extension) was used to design the combined attribute level scenarios of the experiment in the full factorial design, SPSS (version 21) was used for the data encoding and manipulation, and Stata (version 14.2) was used to estimate the mixed logit WTP-space model.

The $D$-optimality criterion is applied, which is the most popular optimality criteria used to design DCEs. The $D$-optimal choice designs for two-level attributes of any choice set size stem from the work of Burgess and Street (2003), which was extended to apply to attributes with any number of levels by Burgess and street (2005). The $D$-optimality criterion seeks to maximize the determinant of the information matrix in an equation or to minimize its inverse, which is the determinant of the variance-covariance matrix of the parameter estimators. The $D$-optimality criterion considers the covariance. The $D$-criterion value is

$$
D_{B}=\int_{R k}\left\{\operatorname{det}\left(I^{-1}(X, B)\right)\right\}^{\frac{1}{k}} \pi(\beta) d \beta
$$

where the exponent $1 / \mathrm{k}$ can ensure the independence of the dimension $\mathrm{k}$ of the parameter vector $\mathrm{b}$. Minimizing this value results in the $D$-optimal design.

The current status (status quo option) was included in all of the choice sets; this allowed the respondent to not select any of the alternatives provided, which would help to identify the potential to improve the water supply system. The inclusion of the status quo option in the choice sets is also instrumental to achieve welfare measures that are consistent with demand theory (Bateman et al. 2002).

Soon after completing the survey, information about the reasons for objection was gathered from protest respondents through a follow-up question. The purpose was to determine the protest bids (i.e., situations in which the respondents do not agree with the context of the valuation scenarios; in these cases, their stated zero WTP may not be a reflection of their true WTP). However, once the survey was completed, the protest responses and status quo choices were eliminated from further analysis, as suggested by Windle and Rolfe (2013).

\section{Data}

We use the stated-preference data collected from the downstream water users of Addis Ababa (AAWSA customers) in 2015 to identify which water supply option (outcome) the respondents prefer the AAWSA to deliver. Four choice sets with 3 alternative water supply choices, including the reference scenario (Table 3) and
11 specific water attributes, were presented to 322 respondents. In addition, the households were asked to provide various sociodemographic characteristics and respond to follow-up questions. A total of 27 responses (8.4\%) were identified as protest responses and status quo choices. Hence, the remaining 295 responses were included in the choice modeling analysis.

To ensure sample representativeness, we reviewed several studies on sample size determination in addition to conducting a pilot survey on 53 sample households to understand the context of the study population. The study population is homogeneous with regard to the water shortage problems they are facing and somewhat homogeneous in their sociodemographic characteristics. Based on empirical experience, Lancsar and Louviere (2008) indicated that more than 20 respondents per version of a questionnaire is rarely required for a reliable model estimation. Performing a significant post-hoc analysis to identify and estimate covariate effects may require a larger sample size. However, model estimation with large numbers of alternatives remains computationally expensive. Pearmain and Kroes (1990) proposed that for DCE designs in modeling preference data, the rule of thumb is that sample sizes greater than 100 can provide a basis for obtaining a reliable estimate. Moreover, in the context of a mixed logit model, limiting the number of alternatives in the estimation by simple random sampling yields consistent parameter estimates (Lemp and Kockelman 2012). Thus, we assume that the sample size is representative of the study population.

The survey elicited information about the respondents' overall purchasing behavior and attitudes toward the drinking water supply (Table 2). It also asked whether the respondents would be willing to pay a certain amount per year to support water supply improvement efforts. In addition to the WTP elicitation questions, the survey included questions about various sociodemographic characteristics as well as the existing water demand and supply conditions of the households, which must be included in the DCE analysis.

The various combinations of water quality, quantity, and pressure in different standards were labeled as a binary option. Regardless of whether the household picked choice 1 ( $0-1$ dummy) or choice 2 ( $0-1$ dummy), the price of an alternative is fixed depending on the supply option the respondents chose.

\section{Mixed logit WTP space model}

WTP measures have been considered valuable for many reasons. First, by providing information about how people value goods or services, they can directly inform policymakers and thus suggest the pricing of these goods or services (Hanley et al. 2006). Second, in economic evaluations (e.g., cost-benefit analyses), WTP measures 
Table 3 A sample choice set

\begin{tabular}{|c|c|c|c|c|}
\hline Ecosystem attribute & Pictures explaining attributes & Choice 1 & Choice 2 & Status quo \\
\hline $\begin{array}{l}\text { Improvement of water } \\
\text { quality to be supplied by } \\
\text { the municipality }\end{array}$ & & $\begin{array}{l}\text { Moderate water } \\
\text { quality but } \\
\text { drinkable }\end{array}$ & $\begin{array}{l}\text { Risk-free and } \\
\text { high-quality } \\
\text { water for } \\
\text { drinking }\end{array}$ & $\begin{array}{l}\text { High risk of } \\
\text { contamination }\end{array}$ \\
\hline $\begin{array}{l}\text { Enhancement of water } \\
\text { quantity to be supplied by } \\
\text { the municipality }\end{array}$ & & $\begin{array}{c}\text { One month of } \\
\text { shortages annually } \\
\left(2-3 \text { days month }{ }^{-1}\right)\end{array}$ & $\begin{array}{l}\text { No months of } \\
\text { shortages } \\
\text { annually }\end{array}$ & $\begin{array}{c}\text { Two - three } \\
\text { months of } \\
\text { shortages annually } \\
(1 \text { week month-1) }\end{array}$ \\
\hline $\begin{array}{l}\text { Enhancement of water } \\
\text { pressure to be supplied } \\
\text { by the municipality }\end{array}$ & & $\begin{array}{l}\text { Normal pressure } \\
\text { ( } 40 \text { to } 55 \mathrm{PSI} \text { ) }\end{array}$ & $\begin{array}{l}\text { Normal pressure } \\
\text { ( } 40 \text { to } 55 \mathrm{PSI} \text { ) }\end{array}$ & $\begin{array}{l}\text { Unpredictable and } \\
\text { either very low or } \\
\text { very high pressure }\end{array}$ \\
\hline $\begin{array}{l}\text { Compensation to be paid } \\
\text { with the monthly water } \\
\text { bill (in ETB/month) }\end{array}$ & & 12.50 & 29.00 & 0 \\
\hline & & Choice $1 \square$ & Choice $2 \square$ & Status quo $\square$ \\
\hline
\end{tabular}

insight as an important contribution (Loomes 2001; Oliver 2002; Negrín et al. 2008). Third, a measure of WTP can be a suitable tool for relative comparisons and to determine the levels of interest of consumers for goods and services.

WTP measures can be derived from discrete choice models, which are estimated using either DCE data or revealed preference data. Therefore, the WTP for an alternative attribute is computed as the ratio of the attribute coefficient to the price coefficient (Petrin and Train 2003). Mixed logit models are a state-of-the-art tool applied in the analysis of discrete choices, and they are increasingly being applied in economics (Hall et al. 2006; Lancsar et al. 2007; Regier et al. 2009; Hole 2008; King et al. 2007; Patterson and Hardy 2008; Negrín et al. 2008; Özdemir et al. 2009). Any discrete choice random utility model can be estimated by an appropriately specified mixed logit model (McFadden and Train 2000) due to the possibility of constituting heterogeneity in preferences that are distinct from the observed characteristics.

In a mixed logit model estimate, the distribution of preferences stipulated by the researcher follows a certain distribution, such as a normal distribution (Hole and Kolstad 2012). The distribution parameters (e.g., the standard deviation and the mean in the case of a normal distribution) are then estimated using either classical or Bayesian estimation techniques. Because the WTP for an attribute is given by the ratio of the attribute coefficient to the price coefficient, the WTP from a mixed logit model is given by the ratio of two randomly distributed terms (Hole and Kolstad 2012). Subject to the choice of coefficient distributions, this can lead the WTPs to have a heavily skewed distribution, and it may not have a defining moment (Hole 2008). A common approach to address this potential problem is to specify the price coefficient to be fixed. This is a convenient assumption, in which the distribution of the WTPs for an attribute is just the distribution of the attribute coefficient scaled by the fixed price coefficient (Hole 2008). However, it is often unreasonable to assume that all individuals have the same preferences for the price (Meijer and Rouwendal 2006), so this approach implies an undesirable balance between the modeling suitability and reality.

A log-normally distributed price coefficient stipulation is another method that allows the price preferences to be heterogeneous. The price coefficient is constrained to be positive, which ensures that the WTP measures have defined moments, but the resulting WTP distribution can be highly skewed, which may produce unrealistic 
estimates of the means and standard deviations of the WTP (Hole and Kolstad 2012).

A convenient method to address this problem is to estimate the mixed logit model in the WTP space (Hole and Kolstad 2012) rather than in the preference space, as suggested by Train and Weeks (2005). This method involves direct estimation of the WTP distribution by reformulating the model, in which the coefficients represent the WTP measures. In other words, direct estimation of the WTP by reformulating the mixed logit model is possible by placing estimated parameters representing the WTP distribution rather than the usual coefficients, which they call the WTP space in contrast to the conventional WTP preference space method (Train and Weeks 2005).

Thus, the researcher can make a prior inference about the WTP distribution rather than about the coefficients of the attribute (Hole and Kolstad 2012). The WTP space enables researchers to directly stipulate the WTP distribution and avoids the subjective choice of the WTP distribution that is incurred from the procedure that divides the coefficients of the nonmonetary attributes by the cost coefficient in the WTP preference space approach. This is one of the major advantages of the WTP space over the WTP preference space, and this method has been found to produce more realistic WTP estimates (Hole and Kolstad 2012). Therefore, in this study, we applied a maximum simulated likelihood (MSL) mixed logit WTP space model to estimate the households' WTP for improved water supply.

\section{Model specification}

\section{MSL mixed logit WTP space model}

In this section, we begin with the conventional design of the utility in the preference space and describe the implications for the correlation of the utility coefficients and the implied WTPs. We then reparametrize the model in the WTP space and discuss the implications.

The utility of person $n$, which in this case is the water user, derives from choosing a water supply option indexed by $j$ in choice situation $t$ and is specified as a function of the price, $w_{n j t}$, and other nonmonetary attributes of the water supply choices, $x_{n j t}$ :

$$
U_{n j t}=\alpha_{n} w_{n j t}+\beta{ }_{n} x_{n j t}+\varepsilon_{n j t}
$$

where $\alpha_{n}$ and $\beta_{n}$ are individual-specific coefficients that vary randomly over the water users for the choice option and the other attributes of the choice option, and $\varepsilon_{n j t}$ is a random term (Gumbel-distributed). We assume that $\varepsilon_{\text {nit }}$ is extreme value-distributed with a variance given by $\operatorname{Var}\left(\varepsilon_{\mathrm{njt}}\right)=\mu_{\mathrm{n}}^{2}\left(\pi^{2} / 6\right)$, where $\mu_{\mathrm{n}}$ is an individual-specific scale parameter for water user $n$. Train and Weeks
(2005) show that dividing equation Eq. 1 by the scale parameter $\mu_{\mathrm{n}}$ to obtain its scale-free equivalent does not affect its behavior because the utility is ordinal. However, this results in a new error term that has the same variance for all decision-makers, which is independent and identically distributed (IID) type-one extreme valuedistributed with a constant variance equal to $\left(\pi^{2} / 6\right)$. The utility coefficients are defined as $\lambda_{n}=\alpha_{n} / \mu_{n}$ and $c_{n}=\beta_{n} /$ $\mu_{n}$, so the utility may be written as follows:

$$
U_{n j t}=\lambda_{n} w_{n j t}+C \prime_{n} x_{n j t}+\varepsilon_{n j t}
$$

Note that if $\mu_{\mathrm{n}}$ varies randomly, the utility coefficient $\lambda_{n}$ and $c_{n}$ will be correlated because $\mu_{n}$ is in the denominator of each coefficient. Therefore, specifying the utility coefficients to be independent implicitly constrains $\mu_{\mathrm{n}}$ to be constant, implying that the random term is homoscedastic, which may not be a realistic assumption (Louviere et al. 2002). If the scale parameter varies and $\alpha_{n}$ and $\beta_{n}$ are fixed, the utility coefficients also vary with perfect correlation. If the utility coefficients have a correlation less than unity, then $\alpha_{n}$ and $\beta_{n}$ inevitably vary in place of, or in addition to, the scale parameter. Even if $\mu_{\mathrm{n}}$ does not vary over the water users (e.g., the standard deviations of the unobserved factors, oversupply option and use are the same for all users), the utility coefficient can be correlated simply due to the correlations between the tastes for various attributes. Train and Weeks (2005) call this specification the model in the preference space. The implied WTP for the water supply attribute is the ratio of the attribute's coefficient to the price coefficient: $\gamma_{\mathrm{n}}=\mathrm{c}_{\mathrm{n} /} \lambda_{\mathrm{n}}=\beta_{\mathrm{n} /} \alpha_{\mathrm{n}}$. Because the WTP for the attributes is given by $\gamma_{n}=c_{n} / \lambda_{n}$, Eq. 2 can be rewritten as follows:

$$
U_{n j t}=\lambda_{n}\left[\omega_{n j t}+\gamma^{\prime} x_{n j t}\right]+\varepsilon_{n j t}
$$

Train and Weeks (2005) call Eq. 3 the WTP space model, and it is also called the "surplus model" by Sonnier et al. (2007). Models (2) and (3) are behaviorally equivalent, but the key point is that standard assumptions about the distributions of $\lambda_{n}$ and $c_{n}$ in the preference space model can lead to unusual WTP distributions. For example, assuming that $\lambda_{n}$ and $c_{n}$ are normally distributed implies that $\gamma_{n}$ is a ratio of two normal distributions, which does not have clear moments. This is an unlikely choice of distribution if we were to directly specify the distribution for the WTP, as we do in the WTP space model. In the WTP space specification, the scale parameter is incorporated in the price coefficient $\lambda_{n}$, whereas it cancels out in the expression for the WTP coefficients. Greene and Hensher (2010) show that the WTP space model can be expressed as a distinct instance of the generalized multinomial logit model proposed by Fiebig et al. (2010). 
In this study, we estimate the WTP for the water supply attributes using the WTP space model. Normally, the coefficients in WTP space models can be estimated using maximum simulated likelihood or Bayesian methods (Train 2009). In this paper, we followed the model estimate using MSL of Thiene and Scarpa (2009). We compute the WTP space from three alternative mixed logit models (fixed, uncorrelated, and correlated) by varying the distribution of the alternative invariant (case-specific) and alternative variant (alternative-specific) regressors of the independent variables. Case-specific variables vary only among the cases, whereas the alternative-specific variables vary among the alternatives (as well as the cases). We selected five case-specific (dysentery, piped water, education, vendor, and income) and six alternative-specific (price, pressure, quality, interruption, shortage, and quantity) variables. Because the attribute coefficients are assumed to be random, the model allows a random scale; hence, the price coefficient is assumed to be log-normally distributed.

The first model is the fixed model, which specifies fixed WTP coefficients for all of the alternative variant variables and most of the alternative invariant variables (i.e., pressure, quantity, quality, interruptions, dysentery, piped water, education, and shortage), normal distribution WTP coefficients for some alternative invariant regressors (i.e., income and vendor), and log-normally distributed coefficients for the price. The second model is an uncorrelated model, which specifies normally distributed WTP coefficients for all of the alternative invariant and some selected of the alternative specific regressors (i.e., pressure and interruptions) and log-normally distributed coefficients for the price and selected alternative variant regressors (i.e., quantity, quality, and shortage). The third model is a correlated model, which allows correlations between the selected alternative variant/invariant random variables related to monthly income, paying for water from vendors and water shortages, and with the price coefficient and with each other. All of the commands and the method that the variables (alternative invariant/variant) were entered into the assumed utility equation are based on MIXLOGITWTP (Hole 2016). For detailed information about the commands, see the description of the commands and syntax for MIXLOGITWTP in the declaration section.

\section{Results and discussion}

\section{Descriptive statistics}

The socioeconomic characteristics of the downstream resource users involved in the survey are presented in Table 4. The respondents had lived in the city for between 1 and 70 years and had ages of 20 to 80 years with an average age of 45 years. Of the households, $48 \%$ were male-headed, and the remaining $52 \%$ were female-headed, of which $70 \%$ were married. Approximately $66 \%$ of the surveyed household heads were first degree and above in education, and 52\% were employed permanently and thus have sustained means of income. The monthly incomes in the sample ranged from 2703 to 19,643 ETB with an average of 5592 ETB. The households were also asked to describe and label their standard of living; 67\% believed their current living conditions are worse than 10 years ago due to the increasing cost of living, whereas $33 \%$ believed that their current living conditions are better than 10 years ago. Approximately $94 \%$ of the households had an installed piped water system at home, whereas the remaining $6 \%$ access water from other sources.

Approximately $58 \%$ of the households were living in their own house, approximately $99 \%$ have a latrine facility, and $94 \%$ have piped water installed. The households were also assessed in terms of their overall water supply satisfaction, including taste, water quality, and pressure. Table 4 shows the perceptions of the surveyed households toward the overall water supply. On average, 49\% of the households were dissatisfied with the water supply system. Similarly, $50 \%$ of the surveyed households were unhappy with the water availability (quantity), and $51 \%$ were unhappy with the water quality. The surveyed households had been living in the area for an average of more than 35 years. Approximately 14\% of the respondents had encountered dysentery over the previous 12 months, and only $43 \%$ of the respondents believed the supplied water is risk-free. The surveyed respondents were willing to contribute an average of 150.5 ETB as a one-off lump sum payment to kick off the EBWSM activities. Similarly, $78 \%$ were willing to pay a certain amount of money monthly toward EBWSM intervention programs. Generally, $70 \%$ of the households want the AAWSA to continue managing the proposed water management and supply system.

\section{Empirical findings Fitting WTP space models}

The salient characteristic of the WTP space model is that the estimated parameters are also the parameters of the indirect WTP distributions. Table 5 shows the estimation results (coefficients) for the three models (fixed, uncorrelated, and correlated) in the WTP space. The estimate for each parameter is the mean and variance of 1000 draws, and the standard error for a measure of the statistical accuracy of an estimate is the standard deviation of the distribution (Petrin and Train 2003). The estimates given in Table 5 for the three models are the means and variances of the coefficients, which makes direct interpretation difficult. Hence, Table 6 gives the means and standard deviations of the coefficients based 
Table 4 Descriptive statistics for the variables used in this study: mean and standard deviation (SD)

\begin{tabular}{|c|c|c|c|c|c|}
\hline Variables & Description & Mean & SD & Min & Max \\
\hline Age & Age of the household head & 45.32 & 15.23 & 20 & 80 \\
\hline Head & $=1$ if the household head is male and zero otherwise. & 0.48 & 2.74 & 0 & 1 \\
\hline Marital status & $=1$ for those who are married and zero otherwise & 0.70 & 0.45 & 0 & 1 \\
\hline Family size & Number of household members or family size & 5.42 & 2.62 & 1 & 21 \\
\hline Living & Number of years the household has lived in the town & 35.32 & 15.41 & 1 & 70 \\
\hline Housing & $=1$ if households possess own house and zero otherwise & 0.58 & 0.51 & 0 & 1 \\
\hline Education & Household head's education level (from illiterate to advanced degrees) & 5.491 & 1.87 & 1 & 9 \\
\hline Employment & $=1$ if the household head is permanently employed and zero otherwise & 0.52 & 0.49 & 0 & 1 \\
\hline Income & Average monthly income of the household (in 000) & 5.592 & 2.59 & 2.703 & 19.643 \\
\hline Standard of living & $=1$ if the household's standard of living has improved compared to 10 years ago and zero otherwise & 0.33 & 0.47 & 0 & 1 \\
\hline Latrine facility & $=1$ if the household has an installed private latrine facility at home and zero otherwise & 0.99 & 0.233 & 0 & 1 \\
\hline [Piped water] & $=1$ if the household has installed piped water at home and zero otherwise & 0.94 & 0.234 & 0 & 1 \\
\hline [Taste of water] & $=1$ if household is satisfied by the taste of the water provided by the source and zero otherwise & 0.49 & 0.500 & 0 & 1 \\
\hline $\begin{array}{l}\text { [Interruptions/water } \\
\text { cut] }\end{array}$ & Number of water-cut days per week & 2.25 & 1.156 & 2 & 6 \\
\hline [Shortage] & Hours of the day that the household often experiences water shortages & 10.57 & 6.965 & 2 & 24 \\
\hline [Travel time] & Walking or travel time to the water point and back in minutes & 1.10 & 0.415 & 1 & 2 \\
\hline [Dysentery] & $=1$ if the household has faced dysentery over the past 12 months and zero otherwise & 0.14 & 0.350 & 0 & 1 \\
\hline [Satisfaction] & $=1$ if the household is satisfied by the overall water supply system and zero otherwise & 0.51 & 0.513 & 0 & 1 \\
\hline [Health risk] & $=1$ if the household believed that the supplied water is risk-free and zero otherwise & 0.43 & 0.495 & 0 & 1 \\
\hline [Vendor] & $=1$ if the household purchases water from vendors and 0 otherwise & 0.15 & 0.35 & 0 & 1 \\
\hline [Participation] & $\begin{array}{l}=1 \text { if the household is willing to participate in meetings and workshops on water supply issues and zero } \\
\text { otherwise }\end{array}$ & 0.67 & 0.468 & 0 & 1 \\
\hline [Management] & $=1$ if the household prefers the AAWSA to manage the improved water supply and zero otherwise & 0.70 & 0.460 & 0 & 1 \\
\hline Quality & $\begin{array}{l}=1 \text { if the household has access to risk-free standard quality water for drinking and cooking daily and zero } \\
\text { otherwise }\end{array}$ & 0.49 & 0.500 & 0 & 1 \\
\hline Quantity & $=1$ if the household has access to enough water for drinking and cooking daily and zero otherwise & 0.50 & 0.500 & 0 & 1 \\
\hline Pressure & $=1$ if the water pressure is below normal (40-55 PSI) and zero otherwise & 0.498 & 0.500 & 0 & 1 \\
\hline Price & Payment options for available alternatives & 23.51 & 7.64 & 12.5 & 36 \\
\hline WTP & $=1$ if the household is willing to pay for EBWSM interventions and zero otherwise & 0.78 & 0.415 & 0 & 1 \\
\hline \multirow[t]{2}{*}{ Contribution } & One-off lump sum kickoff payment in ETB (tens) by the household for source watershed management activities & 150.55 & 472.92 & 0 & 2000 \\
\hline & Valid N (listwise) & 295 & & & \\
\hline
\end{tabular}

NB: sociodemographic variables (italic), specific water attributes (bracketed), bundle choice option (bold) and payment variables (normal)

on the estimates of Table 5. Results with a mean and standard deviation simplify explanations by providing summary information about the estimates (Petrin and Train 2003), and the estimates generally appear to be convincing.

The WTP space models indicate that allowing for full correlation between the coefficients increases the trend of the simulated log-likelihood at convergence for the estimation means from the mixed $(-184.99)$ and uncorrelated $(-184.97)$ models to the correlated $(-183.20)$ model; thus, the values of simulated log-likelihoods are improved from -196.30 to -183.20 . The estimated means have the same signs and orders of magnitude across the models (with and without correlation) and estimates of MSL. Negative means are observed for single attributes rather than for a bundle of choices. Considering the sign of the utility parameter (estimate), a negative sign indicates that an increase in the variable makes the average customer worse off (decreases their utility as well as the WTP space), whereas a positive sign indicates that an increase in the variable make the average customer better off (increases their utility as well as the WTP space). The signs of these estimates are consistent with our expectations.

Low pressure, the frequency of water cuts or interruptions per week, the frequency of dysentery, lack of access to piped water, a continuous water supply from vendors, extended time of the day that households faced water shortages, and higher prices make the average consumer worse off (Table 6). In contrast, a household's access to sufficient water (i.e., quantity), risk-free and standard water quality, and access to installed piped water all make the average consumer happier (better off). 
Table 5 Estimated coefficients (means and variances) of the three models in the WTP space

\begin{tabular}{|c|c|c|c|c|c|c|c|}
\hline \multirow[b]{2}{*}{ Attribute } & \multirow[b]{2}{*}{ Parameter } & \multicolumn{2}{|l|}{ Fixed } & \multicolumn{2}{|c|}{ Uncorrelated (log-normal) } & \multicolumn{2}{|c|}{ Correlated (random) } \\
\hline & & Estimate & Std. Err & Estimate & Std. Err & Estimate & Std. Err \\
\hline \multirow[t]{2}{*}{ Choice 1} & Mean of Coeff. & 27.02 & 0.135 & 27.00 & 0.135 & 28.05 & 0.140 \\
\hline & Variance of Coeff. & 5.38 & & 5.37 & & 5.82 & \\
\hline \multirow[t]{2}{*}{ Choice 2} & Mean of Coeff. & 27.96 & 0.326 & 27.48 & 0.387 & 32.25 & 0.403 \\
\hline & Variance of Coeff. & 31.29 & & 44.17 & & 47.81 & \\
\hline \multirow[t]{2}{*}{ Pressure } & Mean of Coeff. & -1.73 & 0.077 & -1.76 & 0.078 & -1.52 & 0.072 \\
\hline & Variance of Coeff. & 1.74 & & 1.79 & & 1.51 & \\
\hline \multirow[t]{2}{*}{ Quantity } & Mean of Coeff. & 2.94 & 0.077 & 2.92 & 0.078 & 2.72 & 0.074 \\
\hline & Variance of Coeff. & 1.75 & & 1.80 & & 1.62 & \\
\hline \multirow[t]{2}{*}{ Quality } & Mean of Coeff. & 5.48 & 0.097 & 5.51 & 0.098 & 5.45 & 0.096 \\
\hline & Variance of Coeff. & 2.77 & & 2.82 & & 2.69 & \\
\hline \multirow[t]{2}{*}{ Interruption } & Mean of Coeff. & -1.66 & 0.056 & $-\vee 1.64$ & 0.058 & -1.59 & 0.066 \\
\hline & Variance of Coeff. & 0.93 & & 0.98 & & 1.29 & \\
\hline \multirow[t]{2}{*}{ Dysentery } & Mean of Coeff. & -0.98 & 0.056 & -0.96 & 0.057 & -0.93 & 0.063 \\
\hline & Variance of Coeff. & 0.91 & & 0.95 & & 1.16 & \\
\hline \multirow[t]{2}{*}{ Piped water } & Mean of Coeff. & 0.81 & 0.064 & 0.82 & 0.064 & 1.56 & 0.076 \\
\hline & Variance of Coeff. & 1.19 & & 1.21 & & 1.68 & \\
\hline \multirow[t]{2}{*}{ Education } & Mean of Coeff. & 1.56 & 0.056 & 1.54 & 0.058 & 1.58 & 0.066 \\
\hline & Variance of Coeff. & 0.93 & & 0.98 & & 1.29 & \\
\hline \multirow[t]{2}{*}{ Vendor } & Mean of Coeff. & -0.17 & 0.499 & $-0.43^{\mathrm{a}}$ & 0.421 & -1.00 & 0.605 \\
\hline & Variance of Coeff. & 0.01 & & $0.00^{b}$ & & 1.00 & \\
\hline \multirow[t]{2}{*}{ Income } & Mean of Coeff. & 8.43 & 0.144 & $8.55^{\mathrm{a}}$ & 0.152 & 9.07 & 0.037 \\
\hline & Variance of Coeff. & 0.00 & & $4.82^{\mathrm{b}}$ & & 2.69 & \\
\hline \multirow[t]{2}{*}{ Shortage } & Mean of Coeff. & -1.75 & 0.086 & $-1.76^{\mathrm{a}}$ & 0.087 & -2.88 & 0.115 \\
\hline & Variance of Coeff. & 0.01 & & $0.00^{\mathrm{b}}$ & & 7.54 & \\
\hline \multirow[t]{2}{*}{ Price } & Mean of In (Coeff.) & $-0.14^{\mathrm{a}}$ & 0.018 & $-0.14^{\mathrm{a}}$ & 0.018 & $-0.27^{\mathrm{a}}$ & 0.244 \\
\hline & Std. dev. of In (Coeff.) & 0.02 & & 0.02 & & 0.52 & \\
\hline \multicolumn{2}{|c|}{ SLL at convergence } & -184.99 & & -184.97 & & -183.20 & \\
\hline \multicolumn{2}{|c|}{ No. of iterations at convergence } & 3 & & 7 & & 8 & \\
\hline
\end{tabular}

${ }^{\mathrm{a}}$ Mean of In (coefficient)

${ }^{b}$ Variance of In (coefficient)

Therefore, all other things being equal, the respondents prefer a bundle of supply options with risk-free and high-quality water at normal pressure (40 to 55 PSI) with no months of shortages in all of the models. They prefer access to sufficient water daily rather than occasionally insufficient water supply as well as access to risk-free and standard quality water for drinking and cooking rather than water with questionable quality that is potentially risky. In terms of disease, they prefer to be free from incidents of dysentery. In addition, they prefer to have piped water and an uninterrupted water supply. Surprisingly, a water supply by a vendor that mitigates most of the water shortages is not preferred by households, perhaps because the provision of water by vendors might be more expensive than water provided by the agency. Households prefer no extended water shortages during the day. The coefficients for the dysentery, piped water supply, and vendor supply attributes are insignificant in all of the models.

\section{Fixed WTP space model}

According to the coefficients and WTPs of the model's bundle options, on an "all other things equal" basis, high WTP is associated more with choice 2 than with choice 1 ; hence, households are more likely to be willing to pay for choice 2 over choice 1 . Choice 1 has an estimated mean of 27.02 and an estimated standard deviation of 2.319. Therefore, $0.5 \%$ of the distribution is willing to pay less than $21 \mathrm{ETB}$, and $99.5 \%$ is willing to pay more than $21 \mathrm{ETB}$, of which approximately $49.1 \%$ is willing to 
Table 6 Estimated coefficients (means and standard deviations) of the three models in the WTP space

\begin{tabular}{|c|c|c|c|c|c|c|}
\hline \multirow{3}{*}{ Attribute } & \multicolumn{2}{|l|}{ Fixed } & \multicolumn{2}{|c|}{ Uncorrelated (lognormal) } & \multicolumn{2}{|c|}{ Correlated (random) } \\
\hline & \multicolumn{2}{|l|}{$\overline{\text { WTP }}$} & \multicolumn{2}{|l|}{$\overline{\text { WTP }}$} & \multicolumn{2}{|l|}{$\overline{\text { WTP }}$} \\
\hline & Mean & SD & Mean & SD & Mean & SD \\
\hline Choice 1 & 27.01557 & 2.319 & 27.002 & 2.318 & 28.053 & 2.412 \\
\hline Choice 2 & 27.95799 & 5.593 & 27.478 & 6.646 & 32.251 & 6.914 \\
\hline Pressure & -1.72804 & 1.319 & -1.758 & 1.340 & -1.518 & 1.229 \\
\hline Quantity & 2.944709 & 1.324 & 2.924 & 1.340 & 2.720 & 1.273 \\
\hline Quality & 5.479457 & 1.665 & 5.508 & 1.680 & 5.448 & 1.641 \\
\hline Interruption & -1.66327 & 0.967 & -1.637 & 0.991 & -1.591 & 1.137 \\
\hline Dysentery & -0.9824 & 0.954 & -0.957 & 0.975 & -0.929 & 1.078 \\
\hline Piped water & 0.813201 & 1.092 & 0.815 & 1.098 & 1.563 & 1.297 \\
\hline Education & 1.56327 & 0.963 & 1.537 & 0.989 & 1.581 & 1.137 \\
\hline Vendor & -0.16659 & 0.077 & -0.432 & 0.019 & -0.997 & 1.000 \\
\hline Income & 8.426616 & 0.045 & 8.551 & 0.024 & 9.071 & 1.640 \\
\hline Shortage & -1.75488 & 0.095 & -0.172 & 0.005 & -2.883 & 2.746 \\
\hline Price & -0.872 & 0.110 & -0.882 & 0.174 & -0.781 & 0.146 \\
\hline
\end{tabular}

pay between 21 and $27 \mathrm{ETB}$, and $49.9 \%$ is willing to pay between 27 and 33 ETB. The number of households willing to pay more than 33 ETB is $0.5 \%$ of the distribution, which is not surprising considering that the choices and WTP are sensitive to and associated with service quality, price, and household income. Based on the WTP distribution, this alternative has the smallest number of households that are willing to pay the maximum price option and the largest share of households that are willing to pay between 27 and 33 ETB.

Choice 2 has an estimated mean of 27.96 and an estimated standard deviation of 5.593. This corresponds to $10.75 \%$ of the distribution being willing to pay less than 21 ETB and $89.25 \%$ being willing to pay 21 ETB. Approximately $32.5 \%$ of the distribution is willing to pay between 21 to $27 \mathrm{ETB}, 38.34 \%$ is willing to pay between 27 and $33 \mathrm{ETB}$, and the remaining $18.41 \%$ is willing to pay more than 33 ETB. Like choice 1, this alternative also has the largest share of households that are willing to pay between 27 and 33 ETB. In contrast, choice 2 includes a relatively large number of respondents whose WTP is focused on the extreme price option.

\section{Uncorrelated WTP space model}

As specified in the WTP space model, the uncorrelated model has a random coefficient for each variable, and the WTPs are assumed to be uncorrelated over the attributes. We estimated a model with the utility specified as in Eq. 3, where the coefficient of each nonprice attribute is the product of the WTP for that attribute times the price coefficient (Hole and Kolstad 2012), and the model allows for a random scale.
The price coefficient $-\lambda \mathrm{n}$ is given an independent lognormal distribution. The elements of $\omega n$ (WTPs) associated with the cost of the vendor-supplied water, water shortage, and household income are also specified to be independently lognormal. These variables are expected to have the same sign for all of the respondents with only their magnitudes differing over respondents. Specifying a coefficient to be log-normally distributed implies that the WTPs for all individuals are positive, but negative WTPs are managed by entering the attribute multiplied by -1 in the model (Hole 2016). The mean and variance of the log of the coefficient are estimated, and the mean and standard deviation of the coefficient itself are calculated from these estimates. The coefficients of $\omega$ associated with choice 1 , choice 2 , pressure, quantity, quality, interruption, dysentery, and piped water are instead given independent normal distributions with means and variances that are predicted. The simulation was performed using 1000 Halton draws for each sampled respondent. In this case, however, the chosen distributions for the nonmonetary attributes represent the WTP distributions for these attributes. When the WTPs are normally distributed for an attribute and the price coefficient is lognormal, the coefficient of the attribute is not normal (Petrin and Train 2003). Moreover, due to the common influence of the price coefficient on the other coefficients, an uncorrelated WTP implies correlated coefficients (Petrin and Train 2003).

For the bundle options, similar to the fixed model, the distribution of the coefficients in the uncorrelated WTP space model indicates that the respondents placed a higher value on choice 2 over choice 1 . Choice 1 has an estimated mean of 27 and an 
estimated standard deviation of 2.32. Like the fixed model, $0.5 \%$ of the distribution is willing to pay less than $21 \mathrm{ETB}$, and $99.5 \%$ is willing to pay more than 21 ETB, of which approximately $49.5 \%$ is willing to pay between 21 and $27 \mathrm{ETB}$, and $49.5 \%$ is willing to pay between 27 and 33 ETB. WTPs greater than 33 ETB represent $0.5 \%$ of the distribution, which is not surprising because in most cases, the choices of services provided (i.e., water) and WTP are sensitive to and associated with service quality, price, and income. In this choice alternative, the distribution of WTP therefore includes the smallest number of households that are willing to pay the maximum price option and the largest share of households willing to pay between 21 and 33 ETB.

Choice 2 has an estimated mean of 27.45 and an estimated standard deviation of 6.45 . This corresponds to $16.5 \%$ of the distribution being willing to pay less than $21 \mathrm{ETB}$, and the remaining $83.5 \%$ is willing to pay more than $21 \mathrm{ETB}$. When considering the lowest price alternative, approximately $0.5 \%$ of the distribution is willing to pay less than $12.5 \mathrm{ETB}$, and $99.5 \%$ is willing to pay more. Nearly $33.4 \%$ of the distribution is willing to pay between 21 and $27 \mathrm{ETB}$, and $29.67 \%$ is willing to pay between 27 and 33 ETB. Approximately 20.32\% of the distribution is willing to pay more than 33 ETB. Surprisingly, this alternative includes a relatively significant number of respondents with WTP for the extreme price option.

\section{Correlated WTP space model}

For both choices, the results of the model with correlated coefficients have the highest means (28.05 for choice 1 and 32.25 for choice 2) with the fewest households that prefer to pay the least $(0.2 \%$ for choice 1 and $5.26 \%$ for choice 2 ). Like the other two models, the respondents placed a higher value on choice 2 over choice 1 , which is shown by the distribution of the coefficients. Choice 1 has an estimated mean of 28.05 and an estimated standard deviation of 2.412. Approximately $0.2 \%$ of the distribution is willing to pay less than $21 \mathrm{ETB}$, and $99.8 \%$ is willing to pay more than $21 \mathrm{ETB}$, of which $33.16 \%$ is willing to pay between 21 and 27 ETB, and $64.62 \%$ is willing to pay between 27 and 33 ETB. Households willing to pay more than 33 ETB represent $2.02 \%$ of the distribution.

Choice 2 has an estimated mean of 32.25 and an estimated standard deviation of 5.914, which corresponds to $5.26 \%$ of the distribution being willing to pay less than $21 \mathrm{ETB}$ and $94.74 \%$ being willing to pay more. Approximately $17.1 \%$ of the distribution is willing to pay between 21 and 27 ETB, and $32.02 \%$ is willing to pay between 27 and 33 ETB. Those who are willing to pay more than 33 ETB make up approximately $45.62 \%$ of the distribution. In contrast to the other two models and alternatives, the number of respondents whose WTP is for the extreme price option in choice 2 of the correlated model is remarkably large (nearly $46 \%$ ).

Although all three models are types of mixed logit willingness to pay space models, they all vary in terms of allowing or not allowing random and/or fixed scales, estimations of the simulated log-likelihood at convergence, implied WTP distributions, and how well the model fits the observed data. We use the models to compare the specifications across the three WTP space models. The $\log$-likelihood is considerably higher for the correlated model than for the other two models. The same is true for the WTP distributions; hence, the correlated WTP space model fits the data well and appears to be more reasonable. The main distinction is that the means and especially the standard deviations of the WTPs for the fixed and uncorrelated WTP space models are smaller than those for the correlated WTP space model. The correlations are relatively high because each WTP is multiplied by the common price coefficient. In conclusion, for both the coefficients and WTP values, estimating the distributions after restricting the attributes to be fixed and not allowing them to correlate with selected variables and with each other results in smaller means and standard deviations than when the distributions are estimated by allowing correlations.

\section{Correlations}

The correlations between the coefficients of the WTP measures (Table 7) are derived from the correlated WTP space model. The results in the tables show that there is a high degree of correlation between the coefficients of the WTP measures. In particular, the WTP for the water shortage and vendors supply coefficients are correlated negatively with the income coefficient and positively with the price coefficients. The respondent's income and price alternatives are also positively correlated.

The high negative correlations of the income coefficient with shortage and vendor supply suggests that to fill the supply gap (i.e., shortage), households who earn higher incomes may provide themselves with extra water storage tanks, so they are not as dependent on vendors. This may also indicate that lower-income respondents

Table 7 Correlations between the WTP measures and the income coefficient

\begin{tabular}{lllll}
\hline Rho correlation & & & & \\
\hline & Income & Shortage & Vendor supply & Price \\
\hline Income & 1 & & & \\
Shortage & -0.97 & 1 & 1 & \\
Vendor supply & -0.72 & 0.75 & 0.27 & 1 \\
Price & 0.24 & 0.30 & & \\
\hline
\end{tabular}


are unable to secure a supplemental water storage container and hence face water scarcity, which further encourages them to buy water from vendors.

Positive correlations are observed between prices and the water shortage and vendor supply. This suggests that increasing the frequency of water shortages may increase a household's dependence on purchasing from water vendors. This encourages them to make WTP decisions even for higher payment options (price). The price coefficient is positively correlated with income, implying that the WTP of a household increases as their income grows.

\section{Marginal effects: changes in probabilities}

The marginal effect estimates the change in the likelihood of an outcome due to a change in $x_{\mathrm{k}}$ while holding all other independent variables constant (Long and Freese 2006). The main idea is that one variable changes while the others do not. For each discrete and continuous variable, the calculated marginal effects are diverse; thus, two varieties of marginal effects are estimated: marginal change and discrete change. A marginal change computes the effect of an instantaneous or infinitely small change in $X_{k}$, whereas a discrete change computes the effect of a discrete or finite change in $X_{k}$. A marginal change is the rate of change in the likelihood of an infinitely small change in $x$ while other variables remain constant. Because the effect is computed with a partial derivative, some authors refer to this as the partial change or partial effect. In contrast, a discrete change, which is sometimes called a first difference, is the actual change in the predicted probability for a given change in $x_{\mathrm{k}}$ while the other variables are held constant. The discrete change indicates how much the probability actually changes for a given change in a variable.

Long and Freese (2006) showed that if the probability curve used to evaluate a change is approximately linear, the effect on the probability of an outcome of a unit change in the variable will be approximated by the marginal change. The best way to determine how well the marginal effect approximates the change is to compute the discrete change (Long and Freese 2006). Thus, in this study, we examine both the discrete change and the marginal change. Discrete changes of one unit, one standard deviation, from minimum to maximum, and between other percentiles, which indicate the actual changes in the probability for a specific change in $x_{\mathrm{k}}$, were assessed. For the marginal change, the average marginal change is assessed.

Marginal effects are fundamental for interpreting nonlinear models, especially using $\mathrm{m}$-change, which creates compact tables that contain many types of marginal effects. It is a method to rapidly measure the maximum potential impacts of both factors and continuous variables over the range. Normally, changes are computed as observed; the change for each observation is computed from the estimation sample and then averaged. These are sometimes called average marginal effects. For continuous variables, the rows labeled marginal contain the average marginal changes and are identical to what is computed using margins, $\operatorname{dydx}\left({ }^{*}\right)$. For binary factor (categorical) variables, m-change computes the average discrete change as the variable changes from 0 to 1 . By default, for continuous variables, $\mathrm{m}$-change also computes two types of discrete changes. The unit change, which is labeled +1 , is the change in the prediction as the variable changes from its observed value to its observed value plus 1 (Long and Freese 2006). The change in the standard deviation, which is labeled $+\mathrm{SD}$, is the change in the prediction as the variable changes from its observed value by one standard deviation. The amount (range) option computes the discrete changes as $x$ changes from its minimum to its maximum, and the trim (\#) option can also be used to compute the change between other percentiles.

The descriptive statistics show that the income variable (in thousands of ETB) has a range of approximately 16,940 ETB. Hence, although a unit change (1000 difference in income) is small for describing the effect of income on WTP, it appears to be reasonable given the differences in income. By default, $\mathrm{m}$-change computes discrete changes for both a 1-unit change and a standard deviation change in income, and we use brief to suppress showing the average probabilities. The average predicted probabilities of the households' WTP are 52.05, 47.34, and 60.85 for the fixed, uncorrelated, and correlated model estimates, respectively (Table 8 ).

While holding the other variables at their observed values, increasing the income by one standard deviation (approximately $2579.00 \mathrm{ETB}$ ) increases the probability of the households' WTP by averages of 22.5 (fixed model), 5.8 (uncorrelated model), and 23.6 (correlated model), with all effects significant at the 0.01 level. These results are consistent with those of Hensher et al. (2005), who conclude that income significantly influences households' WTP for improved water services. In contrast, Hanley et al. (2006) reported that poorer groups are willing to give up higher fractions of their income for environmental improvements than richer groups.

An increase of one standard deviation in the log of the anticipated price (approximately 7.64) decreases the probability of WTP by averages of 14.81 (fixed model), 14.79 (uncorrelated model), and 13.42 (correlated model), with all effects significant at the 0.001 level. This result is consistent with the findings of Hensher et al. (2005) that the price elasticity of the demand for water characteristics is normally negative because the demand curve slopes downward, which implies that an increase 
Table 8 Marginal effects (m-change, delta option of a five-unit change above the base value and percentile changes) of selected significant parameters

\begin{tabular}{|c|c|c|c|c|c|c|}
\hline & \multicolumn{2}{|l|}{ Fixed } & \multicolumn{2}{|c|}{ Uncorrelated } & \multicolumn{2}{|c|}{ Correlated } \\
\hline & Change & $p$ value & Change & $p$ value & Change & $p$ value \\
\hline \multicolumn{7}{|l|}{ Income } \\
\hline 1 & 8.179 & 0.004 & 2.113 & 0 & 8.582 & 0.005 \\
\hline SD & 22.48 & 0.004 & 5.808 & 0 & 23.588 & 0.005 \\
\hline Marginal & 8.179 & 0.004 & 2.113 & 0 & 8.582 & 0.005 \\
\hline Delta(5) & 40.895 & 0.004 & 10.567 & 0 & 42.912 & 0.005 \\
\hline $5 \%$ to $95 \%$ & 58.34 & 0.004 & 15.074 & 0 & 59.335 & 0.005 \\
\hline \multicolumn{7}{|l|}{ Price } \\
\hline 1 & -1.937 & 0 & -1.935 & 0 & -1.756 & 0 \\
\hline SD & -14.806 & 0 & -14.79 & 0 & -13.423 & 0 \\
\hline Marginal & -1.937 & 0 & -1.935 & 0 & -1.756 & 0 \\
\hline Delta(5) & -9.687 & 0 & -9.676 & 0 & -8.782 & 0 \\
\hline $5 \%$ to $95 \%$ & -45.529 & 0 & -45.478 & 0 & -41.276 & 0 \\
\hline \multicolumn{7}{|l|}{ Education } \\
\hline 1 & 0.043 & 0.032 & 0.055 & 0.041 & 0.082 & 0.02 \\
\hline SD & 0.711 & 0.032 & 0.903 & 0.041 & 1.348 & 0.02 \\
\hline Marginal & 0.043 & 0.032 & 0.055 & 0.041 & 0.082 & 0.02 \\
\hline Delta(5) & 0.217 & 0.032 & 0.276 & 0.041 & 0.412 & 0.02 \\
\hline $5 \%$ to $95 \%$ & 1.862 & 0.032 & 2.365 & 0.041 & 3.529 & 0.02 \\
\hline \multicolumn{7}{|l|}{ Quality } \\
\hline 1 & 5.464 & 0.001 & 5.499 & 0.001 & 5.426 & 0.001 \\
\hline SD & 12.966 & 0.001 & 13.048 & 0.001 & 12.876 & 0.001 \\
\hline Marginal & 5.464 & 0.001 & 5.499 & 0.001 & 5.426 & 0.001 \\
\hline Delta(5) & 27.321 & 0.001 & 27.494 & 0.001 & 27.131 & 0.001 \\
\hline $5 \%$ to $95 \%$ & 31.094 & 0.001 & 31.29 & 0.001 & 30.877 & 0.001 \\
\hline \multicolumn{7}{|l|}{ Quantity } \\
\hline 1 & 2.936 & 0.027 & 2.903 & 0.031 & 2.715 & 0.033 \\
\hline SD & 5.09 & 0.027 & 5.032 & 0.031 & 4.708 & 0.033 \\
\hline Marginal & 2.936 & 0.027 & 2.903 & 0.031 & 2.715 & 0.033 \\
\hline Delta(5) & 14.68 & 0.027 & 14.513 & 0.031 & 13.576 & 0.033 \\
\hline $5 \%$ to $95 \%$ & 12.81 & 0.027 & 12.664 & 0.031 & 11.846 & 0.033 \\
\hline Average prediction & 52.046 & & 47.338 & & 60.847 & \\
\hline
\end{tabular}

in price is expected to decrease the demand. This finding is also consistent with Null et al. (2012), who states that because demand is very sensitive to price, a household's willingness to pay for cleaner water is often less than the cost of supply. This suggests that households prefer lower-cost water supply options.

In addition, increasing the households' educational attainment by one level (e.g., from illiteracy to basic education) increases the probability of the households' WTP by averages of $0.04,0.05$, and 0.08 for the fixed, uncorrelated, and correlated models, respectively. Similarly, increasing the households' educational attainment by one standard deviation (by approximately two levels, such as from primary schooling to college diploma) increases the probability of the households' WTP by averages of 0.7 (fixed model), 0.9 (uncorrelated model), and 1.35 (correlated model), all of which are significant at the 0.05 level. This may be because the educational level of the households increases their awareness and exposure level, and they will thus be more receptive to a policy that leads to improved livelihood and welfare. This finding is consistent with the results of Haq et al. (2007) and Adenike and Titus (2009), who found that education level has a direct relationship with WTP for safe 
drinking water. In addition, Sattar et al. (2007) confirmed that a household's exposure to mass media and formal education substantially affects their WTP for different water-cleaning methods, which demonstrates that the education of the household's decision-maker is a significant determinant of their WTP.

A marginal change and a 1-unit discrete change in a households' monthly income (1000.00 ETB) are associated with increases in the probability of the households' WTP of 8.2, 2.1, and 8.6 in the fixed, uncorrelated, and correlated models, respectively. The marginal change and a unit discrete change in alternative payment options (nearly 2.5 ETB) are associated with 1.94, 1.94, and 1.76 decreases in the probability of households' WTP in the three models, respectively. These results indicate that the marginal change and a unit discrete change are similar, which reflects that the probability curves are nearly linear for a change of 1 in either variable.

In addition to one unit and standard deviation changes, a change in a specific amount was also explored to investigate the relationship and effect on WTP. Hence, a discrete change in a household's monthly income from the base value to five units above the base value (approximately $5000.00 \mathrm{ETB}$ ) is computed using the delta option in m-change (i.e., delta 5). A 5000 ETB change in a household's monthly income is associated with average increases of 40.9 and 43 in the probability of the households WTP in the fixed and correlated models, respectively, and an increase of only 10. 6 in the uncorrelated model. A change in the alternative price by five units above the base value of approximately 20 ETB (computed as the average of the difference between consecutive price options multiplied by five units) is associated with decreases in the probability of the households' WTP of 9.7 in the fixed and uncorrelated models and 8.8 in the correlated model.

M-change is a quick way to assess the maximum potential impacts of both continuous variables and factor variables over their ranges (Long and Freese 2006). Changes over the range indicate the expected change in the outcome probability in the unlikely event of large changes in a variable while holding the other variables constant. Although such large changes are unlikely to occur in the real world, it allows the greatest effect to be identified. However, because the range of a variable can be influenced by even a single extreme observation (e.g., one person with an unusually high income), using trimmed ranges for some variables is the best option.

A trimmed range might be more informative for a variable such as monthly income, where only a few households might have very high incomes. Thus, by specifying trim (5), we examined the effect of a change from the 5 th percentile of income to the 95 th percentile. The effects are substantially higher, most noticeably for the fixed and correlated models. On average, the probabilities of the households' WTP will increase by 58.3, 15.1, and 59.3 if the respondents changed from the 5th percentile of income to the 95th percentile $(p<0.01$, two-tailed). On the other hand, the probability of the households' WTP will decrease by 45.5 for the fixed and uncorrelated models and by 41.3 for the correlated model if the alternative changed from the 5th percentile of price to the 95th percentile $(p<0.001$, two-tailed). Generally, the changes in the predicted probability of a household's WTP are higher for the correlated and fixed models than for the uncorrelated model. We can obtain more information about the discrete changes over the range from the starting to ending probabilities by using the centile on the 5th and 95th percentiles (Tables 9 and 10).

Varying a household's monthly income from the 5th percentile to the 95th percentile (i.e., from 2913 to 10,573 ETB) increases the probability of WTP from 5.1 to 63.5 (an increase of 58.3) for the fixed model (Table 10). With a similar change in a households' monthly income, the probabilities of WTP increase from 48.7 to 63.8 (an increase of 15) for the uncorrelated model and from 1.9 to 61.2 (an increase of 59.3) for the correlated model $(p<0.005$, two-tailed). The results show that there is a positive relationship between monthly income and WTP, which indicates that the effect of a households' monthly income is positive and highly statistically significant.

Conversely, shifting the price of alternative choices from the 5th to 95th percentile (i.e., from 12.5 to 36 ETB) decreases the probability of WTP from 76.2 to 30.7 (a decrease of 45.5) in the fixed model, from 85 to 39.5 (a decrease of 45.5) in the uncorrelated model, and from 69.3 to 28 (a decrease of 41.3) in the correlated models $(p<0.00$, two-tailed). Although the discrete change is not significant, the change in household education from the 5th to the 95th percentile (i.e., from basic education to third degree level) increases the probabilities of WTP from 50.5 to 52.4 (an increase of 1.9) in the fixed model, from 58.9 to 61.3 (an increase of 2.4) in

Table 9 The 5th and 95th percentiles of income, price, and education using the centiles

\begin{tabular}{|c|c|c|c|c|c|}
\hline \multirow{3}{*}{$\begin{array}{l}\text { Variable } \\
\text { Income }\end{array}$} & \multirow{3}{*}{$\begin{array}{l}\text { Obs } \\
1180\end{array}$} & \multirow{3}{*}{$\begin{array}{l}\text { Percentile } \\
5\end{array}$} & \multirow{3}{*}{$\begin{array}{l}\text { Centile } \\
2913\end{array}$} & \multirow{2}{*}{\multicolumn{2}{|c|}{$\frac{\text { Binom. Interp. }}{\text { [95\% conf. interval] }}$}} \\
\hline & & & & & \\
\hline & & & & 2913 & 3023 \\
\hline & & 95 & 10,573 & 10,463 & 11,023 \\
\hline \multirow[t]{2}{*}{ Price } & 1180 & 5 & 12.5 & 12.5 & 12.5 \\
\hline & & 95 & 36 & 36 & 36 \\
\hline \multirow[t]{2}{*}{ Education } & 1180 & 5 & 3 & 3 & 4 \\
\hline & & 95 & 8 & 7 & 8 \\
\hline
\end{tabular}


Table 10 Starting and ending probabilities of the discrete changes for the continuous independent variables (income, price, and education) across the three models

\begin{tabular}{|c|c|c|c|c|c|}
\hline & & Change & From & To & $p$ value \\
\hline \multicolumn{6}{|l|}{ Income } \\
\hline \multirow[t]{3}{*}{$5 \%$ to $95 \%$} & Fixed & 58.34 & 5.139 & 63.48 & 0.004 \\
\hline & Uncorrelated & 15.074 & 48.727 & 63.801 & 0 \\
\hline & Correlated & 59.335 & 1.883 & 61.218 & 0.005 \\
\hline \multicolumn{6}{|l|}{ Price } \\
\hline \multirow[t]{3}{*}{$5 \%$ to $95 \%$} & Fixed & -45.529 & 76.234 & 30.705 & 0 \\
\hline & Uncorrelated & -45.478 & 85.008 & 39.53 & 0 \\
\hline & Correlated & -41.276 & 69.266 & 27.99 & 0 \\
\hline \multicolumn{6}{|l|}{ Education } \\
\hline \multirow[t]{3}{*}{$5 \%$ to $95 \%$} & Fixed & 1.862 & 50.527 & 52.389 & 0.854 \\
\hline & Uncorrelated & 2.365 & 58.917 & 61.283 & 0.823 \\
\hline & Correlated & 3.529 & 44.458 & 47.988 & 0.753 \\
\hline
\end{tabular}

the uncorrelated model, and from 44.5 to 48 (an increase of 3.5) in the correlated model.

The results confirm the theory of environmental economics, which assumes that the demand for an improved ES increases with consumer income (McConnell 1997). According to Moffat et al. (2011a, b), those with a higher income were willing to pay for a better water supply system. Similarly, in a study at Chongqing in China, Wang et al. (2010) found that greater WTP is correlated with higher-income households than with lower-income households; households with higher incomes have a higher willingness to pay than lower-income households. High-income households also have higher WTP than middle-income households (Khan et al. 2010). Generally, this result is consistent with the argument that if something is worth having, then it should be worth paying for.

In contrast, several studies have found different results. For example, Cairncross (1990) and World Bank (1996) showed that low-income consumers are willing to pay for water supply services. In addition, Chowdhury (1999) used the contingent valuation technique to predict Dhaka slum dwellers WTP for safe drinking water and found that in an effort to manage water supply-related costs, slum dwellers are willing to pay sufficiently more than others, indicating that to generate funds for water system investment, higher water prices would be financially feasible.

For categorical variables, a household's daily "access to" high-quality water increases the probability of WTP than the opposite "no access to" high-quality water supply. On average, daily access to risk-free high-quality water for drinking and cooking increases a household's probability of WTP from 52 to 65 (an increase of 12.9) in the fixed model, from 60.8 to 73.9 (an increase of 13) in the uncorrelated model, and from 47 to 60 (an increase of 12.9) in the correlated model, with $p=0.001$ (Table 11). Similarly, a household's daily "access to" water supply adequately increases the probability of WTP more than the opposite "no access to" an adequate water supply. These results show that, on average, daily access to sufficient water for drinking and cooking increases a household's probability of WTP from 52 to 57 (an increase of 5.1) in the fixed model, from 60.1 to 65.9 (an increase of 5) in the uncorrelated model, and from 47 to 52(an increase of 4.7) in the correlated model, with $p<0.05$ (Table 11). Generally, the results show that the correlated model fits the data better than the fixed and uncorrelated models.

\section{Conclusion}

In this study, we used mixed logit WTP space models to examine downstream household water users' willingness to pay (WTP) for improved access to or quality of drinking water services based on stated preference data collected from 322 households. Downstream water users were exposed to alternative water supply improvement options, including quality, quantity, and pressure. Three models (fixed, uncorrelated, and correlated) were compared.

The results showed that three-quarters of the households are willing to contribute a certain amount of money on a monthly basis toward EBWSM intervention programs. The average contribution that the respondents were willing to pay was $150.5 \mathrm{ETB}$ as a one-off lump sum to kick off the EBWSM activities. This implies that AAWSA customers are willing to pay to avoid most types of water supply restrictions. In addition, more than

Table 11 Starting and ending probabilities of discrete changes for categorical/factor independent variables (water quality and quantity) across the three models

\begin{tabular}{lllllll}
\hline & & & Change & From & To & $p$ value \\
\hline Quality & Fixed & Access vs no access & 12.966 & 52.046 & 65.012 & 0.001 \\
& Uncorrelated & Access vs no access & 13.048 & 60.847 & 73.895 & 0.001 \\
& Correlated & Access vs no access & 12.876 & 47.338 & 60.213 & 0.001 \\
Quantity & Fixed & Access vs no access & 5.09 & 52.046 & 57.136 & 0.027 \\
& Uncorrelated & Access vs no access & 5.032 & 60.847 & 65.879 & 0.031 \\
& Correlated & Access vs no access & 4.708 & 47.338 & 52.045 & 0.033 \\
\hline
\end{tabular}


$70 \%$ of the households want the AAWSA to continue managing the proposed water management and supply system.

The empirical results indicated that the majority of respondents chose choice 2 over choice 1, implying that households prefer to be supplied with risk-free, high-quality water without interruption at an appropriate flow pressure. The model with correlations fits the data well with the highest simulated log-likelihoods at convergence and gives the best estimates of households' WTP for water improvement schemes. Nearly $46 \%$ of the sampled households were willing to pay more than 33 ETB per month for the monthly water bill, and more than $49 \%$ of the households were willing to pay between $21 \mathrm{ETB}$ and 33 ETB per month. Overall, approximately $95 \%$ of the households were willing to pay more than 21 ETB.

Generally, household WTP is sensitive to scope (i.e., extent of service improvement linked to potable water), household income, affixed price, and the method of stated preference elicitation. In particular, the demand for improved water services is significantly related to the price of service and income and to some extent to the educational attainment of the households. This suggests that the demand for safe drinking water could be higher if income levels are high. Moreover, like household income, the WTP of well-informed households is higher than that of households that are not informed or less aware of the situation, and if people have sufficient access to information and awareness of the health risks associated with inferior water quality, they are more likely to have a higher WTP. Therefore, increasing awareness about the adverse health effects of unsafe drinking water will increase the demand for an improved drinking water supply. Importantly, the influences of these factors follow the theoretical predictions and intuition. In conclusion, mixed logit WTP-space models can help predict household-level WTP well for selected improvements in drinking water access and services in the Legedadie-Dire catchments.

\footnotetext{
Abbreviations

AAWSA: Addis Ababa Water and Sewerage Authority; DAAD: German Academic Exchange Service; DCEs: Discrete choice experiments; DEFRA: Department of Environment, Food and Rural Affairs; EBWSM: Ecosystem-based water supply management; EG: Ephrem Gebremariam; EiABC: Ethiopian Institute of Architecture, Building Construction, and City Development; Eq: Equation; ES: Ecosystem services; ETB: Ethiopian Birr; Fig: Figure; FTU: Formazin turbidity unit; GZ: Gete Zeleke; IFS: International Foundation for Science; IID: Independent and identically distributed; IPBES: Inter-governmental Platform on Biodiversity and Ecosystem Services; LEAP: Leadership Enhancement in Agricultural Program; Ln: Log normal; LULCC: Land use and land cover change; $\mathrm{mH}_{2} \mathrm{O}$ : Meter of water column; $\mathrm{Mm}^{3}$ : Million cubic meters; MPR: Master plan review; MSL: Maximum simulated likelihood; PES: Payment for ecosystem services; PSI: Pounds per square inch; SD: Standard deviations; TEEB: The Economics of Ecosystems and Biodiversity; UK: United Kingdom; USA: United States of America; USD: United States Dollar; WTP: Willingness to pay; YA: Yilikal Anteneh; ZEF: Center for Development Research
}

\section{Acknowledgments}

The authors would like to acknowledge the International Foundation for Science (IFS) for funding this research project, the Borlaug Leadership Enhancement in Agricultural Program (Borlaug LEAP) and the German Academic Exchange Service (DAAD) for providing a fellowship as well as Center for Development Research (ZEF) for making available library and research facilities to realize this research project. Moreover, we express our appreciation to the Ethiopian Institute of Architecture, Building Construction, and City Development (EiABC), Addis Ababa University, for its key role in grant administration.

Description of some command and syntaxes for MIXLOGITWTP The post estimation command mixlogitwtp fits mixed logit models in willingness to pay (WTP) space by using MSL based on \{cmd:mixlogitwtp\} command of (Hole, 2016). All of the \{cmd:mixlogit\} post estimation commands are available after \{cmd:mixlogitwtp\}.

The predicted probabilities (both in and out of sample) are calculated by mixlpred command. The coefficient covariance matrix along with their standard errors are calculated by mixlcov command (which is relevant only when the coefficients are specified to be correlated. While the individuallevel parameters corresponding to the variables in the specified variable list (both in and out of the sample) are calculated using mixlbeta command. Full command of the variables for the fixed (A), uncorrelated (B), and correlated (C) models:

(A) mixlogitwtp Y choice1 choice2 Pressure Quantity Quality Interruptions Dysentry 12 Piped-water Education Shortage, group (GG) id (id2) Price(mPrice) rand(Income Vendor) nrep(1000) burn(50)

(B) mixlogitwtp Y, group (GG) id (id2) Price(mPrice) rand (choicel choice2 Pressure Interruptions Dysentry12 Piped-water Education Vendor Income Quantity Quality Shortage) In(3) nrep(1000) burn(50)

(C) mixlogitwtp Y choice1 choice2 Pressure Quantity Quality Interruptions Dysentry 12 Piped-water Education, group (GG) id (id2) Price (mPrice) rand (Income Vendor Shortage) nrep(1000) burn(50) corr

\section{Funding}

The International Foundation for Science (IFS) financially supported the study under research project Grant No. W/5386-1.

\section{Availability of data and materials}

Please contact the author for data requests.

\section{Authors' contributions}

YA developed the design of the model and the study in total, analyze and evaluated the results, and drafted the manuscript. GZ participated in the study, coordinated and helped evaluation of results. EG participated in the design of the study, managed the database, and helped to draft the manuscript. All authors read and approved the final manuscript.

Ethics approval and consent to participate Not applicable.

Consent for publication Not applicable.

\section{Competing interests}

The authors declare that they have no competing interests.

\section{Publisher's Note}

Springer Nature remains neutral with regard to jurisdictional claims in published maps and institutional affiliations. 


\section{Author details}

${ }^{1}$ Water and Land Resource Center (WLRC), Addis Ababa University, 3880 Addis Ababa, Ethiopia. ${ }^{2}$ Chair of Environmental Planning and Landscape Design, Addis Ababa University, Addis Ababa, Ethiopia.

Received: 31 May 2018 Accepted: 30 January 2019

Published online: 21 March 2019

\section{References}

AAWSA 1994. The study of problem analysis of means to control water quality deterioration of Legadadi reservoir. Final report, 1

AAWSA (2004) Master plan study for Legedadi. Dire and Gafarsa Reservoirs, Addis Ababa, Ethiopia

AAWSA (2011). Business plan from 2011-2020, final report. Addis Ababa, Ethiopia

Adamowicz W, Boxall P, Williams M, Louviere J (1998) Stated preference approaches for measuring passive use values: choice experiments and contingent valuation. Am J Agric Econ 80(1):64-75

Adamowicz W, Louviere J, Williams M (1994) Combining revealed and stated preference methods for valuing environmental amenities. J Environ Econ Manag 26(3):271-292

Adenike AA, Titus OB (2009) Determinants of willingness to pay for improved water supply in Osogbo Metropolis; Osun state, Nigeria. Res J Soc Sci 4:1-6

Ahmad I and Sattar A (2010) Factors determining public demand for safe drinking water (a case study of district Peshawar). Working Papers \& Research Reports, 2010

Akinyemi BE, Mushunje A, Fashogbon AE (2018) Factors explaining household payment for potable water in South Africa. Cogent Social Sciences 4(1): 1464379

Alcamo J, Henrichs T, Rösch T (2017) World water in 2025: global modeling and scenario analysis for the world commission on water for the 21 st century

Andualem G, Yonas M (2008) Prediction of sediment inflow to Legedadi reservoir using SWAT watershed and CCHE1D sediment transport models. Nile Basin Water Engineering Scientific Magazine 1:2008

Anteneh Y, Stellmacher T, Zeleke G, Mekuria W, Gebremariam E (2018a) Dynamics of land change: insights from a three-level intensity analysis of the Legedadie-Dire catchments, Ethiopia. Environ Monit Assess 190:1-22

Anteneh Y, Zeleke G, Gebremariam E (2018b) Assessment of surface water quality in Legedadie and Dire catchments, Central Ethiopia, using multivariate statistical analysis. Acta Ecol Sin 38(2):81-95

Bateman IJ, Carson RT, Day B, Hanemann M, Hanley N, Hett T, Jones-Lee M, Loomes G, Mourato S, Pearce DW and Sugden R (2002) Economic valuation with stated preference techniques: a manual. Economic valuation with stated preference techniques: a manual

Bateman IJ, Lovett AA, Brainard JS (2003) Applied environmental economics: a GIS approach to cost-benefit analysis. Cambridge University Press

Ben, O.O. and Ogunyemi Omotayo, F., (2015). Assessment of water supply situation in Owo, Ondo State, Nigeria: Implications for the Attainment of the Millennium Development Goals. Int J Scientific Res Publications

Bereket B (2006) Evaluation of water supply systems in selected urban poor areas of Addis Ababa, Ethiopia. UNESCO-IHE Institute for Water Education, MSc Thesis MWI

Bonn A, Rebane M, Reid C (2009) 25 ecosystem services: a new rationale for conservation of upland environments

Brixi H (2009) Ethiopia-urban water supply and sanitation project: procurement plan of works from July 1, 2009-July 31, 2010

Bryce J, Boschi-Pinto C, Shibuya K, Black RE, WHO Child Health Epidemiology Reference Group (2005) WHO estimates of the causes of death in children. Lancet 365(9465):1147-1152

Burgess L, Street DJ (2003) Optimal designs for 2 k choice experiments.

Burgess L, Street DJ (2005) Optimal designs for choice experiments with asymmetric attributes. Journal of Statistical Planning and Inference 134(1):288-301.

Butterworth, J., Welle, K., Bostoen, K. and Schaefer, F., (2013). WASH sector monitoring. Achieving water security: lessons from research in water supply, sanitation and hygiene in Ethiopia, pp49-67

Cairncross S (1990) Water supply and the urban poor

Carson, R. and Louviere, J.J., (2010). Experimental design and the estimation of willingness to pay in choice experiments for health policy evaluation (Doctoral dissertation, Oxford University Press)

Casey JF, Kahn JR, Rivas A (2006) Willingness to pay for improved water service in Manaus, Amazonas, Brazil. Ecol Econ 58(2):365-372
Chander P, Tulkens H (2006) The core of an economy with multilateral environmental externalities. In: Public goods, environmental externalities and fiscal competition. Springer, Boston, pp 153-175

Chowdhury, N.T., (1999). Willingness to pay for water in Dhaka slums: a contingent valuation study. Ahmad et al., IUCN-The World Conservation Union, Association of Green Accounting, Environmental Economics in Bangladesh, pp.105-116

Colby BG, McGinnis MA, Rait K (1989) Procedural aspects of state water law: transferring water rights in the western states. Ariz L Rev 31:697

Connor, R., (2015). The United Nations world water development report 2015 : water for a sustainable world (Vol. 1). UNESCO publishing. Retrived from https://www.riob.org/sites/default/files/IMG/pdf/Water_Sustainable_World.pdf

Coster AS, Otufale GA (2014) Household's water-use demand and willingness to pay for improved water services in ljebu-Ode local government area, Ogun state, Nigeria. J Environ Earth Sci 4:166-174

Crampton A, Ragusa A (2008) My water's fine, isn't it? An exploration of the gendered perception of water quality and security in Australia. Rural Soc 18(3):202-213

DEFRA (2013) Payments for ecosystem services: a best practice guide. Department for Environment Food and Rural Affairs-DEFRA, URS 6-8 Greencoat place, London SW1P 1PL, pp 1-84

Dessalegn M, Merrey DJ (2015) Motor pump revolution in Ethiopia: promises at a crossroads. Water Alternatives 8(2):237-257

Ebba, E., (2006). Groundwater of the Akaki basin (doctoral dissertation, MSc thesis, Addis Ababa University, Addis Ababa, Ethiopia)

Elala, D., (2011). Vulnerability assessment of surface water supply systems due to climate change and other impacts in Addis Ababa, Ethiopia

Engel S, Pagiola S, Wunder S (2008) Designing payments for environmental services in theory and practice: an overview of the issues. Ecol Econ 65(4): 663-674

Fiebig DG, Keane MP, Louviere J, Wasi N (2010) The generalized multinomial logit model: accounting for scale and coefficient heterogeneity. Mark Sci 29(3): 393-421

Freeman AM III, Herriges JA, Kling CL (2014) The measurement of environmental and resource values. New York: Routledge. Retrieved from https://doi.org/10. 4324/9781315780917

Gadgil A (1998) Drinking water in developing countries. Annu Rev Energy Environ 23(1):253-286

Gamtessa, M.M., (2008). Pressure modelling for leakage reduction in Addis Ababa water supply system mains (Saint Paul and Rufael sub systems). Unpublished MSC thesis, Adds Ababa, Ethiopia, Addis Ababa University

Gebresamuel G, Singh BR, Dick $\varnothing$ (2010) Land-use changes and their impacts on soil degradation and surface runoff of two catchments of northern Ethiopia. Acta Agric. Scand. Sect. B Soil Plant Sci. 60(3):211-226

Genius M, Hatzaki E, Kouromichelaki EM, Kouvakis G, Nikiforaki S, Tsagarakis KP (2008) Evaluating consumers' willingness to pay for improved potable water quality and quantity. Water Resour Manag 22(12):1825-1834

Greene WH, Hensher DA (2010) Does scale heterogeneity across individuals matter? An empirical assessment of alternative logit models. Transportation 37(3):413-428

Habitat UN (2016) Urbanization and development emerging futures. World cities report

Hall J, Fiebig DG, King MT, Hossain I, Louviere JJ (2006) What influences participation in genetic carrier testing?: results from a discrete choice experiment. J Health Econ 25(3):520-537

Hanley N, Colombo S, Tinch D, Black A, Aftab A (2006) Estimating the benefits of water quality improvements under the water framework directive: are benefits transferable? Eur Rev Agric Econ 33(3):391-413

Haq, M., Mustafa, U. and Ahmad, I., (2007). Household's willingness to pay for safe drinking water: a case study of Abbottabad district. The Pakistan Development Review, pp1137-1153

Hensher D, Shore N, Train K (2005) Households' willingness to pay for water service attributes. Environ Resour Econ 32(4):509-531

Hoekstra AY, Mekonnen MM, Chapagain AK, Mathews RE, Richter BD (2012) Global monthly water scarcity: blue water footprints versus blue water availability. PLoS One 7(2):e32688

Hole A (2016) MIXLOGITWTP: Stata module to estimate mixed logit models in WTP space, statistical software components S458037, Boston College Department of Economics

Hole AR (2008) Modelling heterogeneity in patients' preferences for the attributes of a general practitioner appointment. J Health Econ 27(4):1078-1094 
Hole AR, Kolstad JR (2012) Mixed logit estimation of willingness to pay distributions: a comparison of models in preference and WTP space using data from a health-related choice experiment. Empir Econ 42(2):445-469 Jideonwo JA (2014) Ensuring sustainable water supply in Lagos, Nigeria Kebede YK, Kebedee T (2012) Application of principal component analysis in surface water quality monitoring. In: Principal Component AnalysisEngineering Applications InTech

Khan H, Iqbal F, Saeed I, Khan I (2010) Estimating willingness to pay for improvements in drinking water quality: evidence from Peshawar, northern Pakistan. Environ Econ 1(2):38-43

Khan KS, Wojdyla D, Say L, Gülmezoglu AM, Van Look PF (2006) WHO analysis of causes of maternal death: a systematic review. Lancet 367(9516):1066-1074

King MT, Hall J, Lancsar E, Fiebig D, Hossain I, Louviere J, Reddel HK, Jenkins CR (2007) Patient preferences for managing asthma: results from a discrete choice experiment. Health Econ 16(7):703-717

Lancaster K (1966) A new approach to consumer theory. J Polit Econ 74(2):132-157

Lancsar E, Louviere J (2008) Conducting discrete choice experiments to inform healthcare decision making. Pharmacoeconomics 26(8):661-677

Lancsar E, Louviere J, Flynn T (2007) Several methods to investigate relative attribute impact in stated preference experiments. Soc Sci Med 64(8):17381753

Lemp JD, Kockelman KM (2012) Strategic sampling for large choice sets in estimation and application. Transp Res A Policy Pract 46(3):602-613

Liemberger R, Brothers K, Lambert A, McKenzie R, Rizzo A and Waldron T (2007) Water loss performance indicators. In Proceedings of IWA Specialised Conference Water Loss (pp. 148-160)

Long JS, Freese J (2006) Regression models for categorical dependent variables using Stata. Stata Press

Loomes, G., (2001). The use of cost-effectiveness thresholds outside the health sector. Costeffectiveness Thresholds: Economic and Ethical Issues

Louviere J, Street D, Carson R, Ainslie A, Deshazo JR, Cameron T, Hensher D, Kohn R, Marley T (2002) Dissecting the random component of utility. Mark Lett 13(3):177-193

Louviere JJ, Hensher DA, Swait JD (2000) Stated choice methods: analysis and applications. Cambridge University Press

Ludi E, Terefe B, Calow R, Birhane G (2013) Ethiopia's water resources, policies, and institutions. Achieving Water Security, p 25

Lusk JL, Norwood FB (2005) Effect of experimental design on choice-based conjoint valuation estimates. Am J Agric Econ 87(3):771-785

McConnell KE (1997) Income and the demand for environmental quality. Environ Dev Econ 2(4):383-399

McFadden, D. and Train, K., (2000). Mixed MNL models for discrete response. J Appl Econometrics, 447-470

Meijer E, Rouwendal J (2006) Measuring welfare effects in models with random coefficients. J Appl Econ 21(2):227-244

Mengesha, A., (2014). GIS-based land suitability analysis; case study of Gefersa watershed (Doctoral dissertation, Addis Ababa University Addis Ababa, Ethiopia)

Mengistu MG, Savage MJ (2010) Open water evaporation estimation for a small shallow reservoir in winter using surface renewal. J Hydrol 380(1-2):27-35

Mesfin M, Belay A (1989) A study of seasonal variation of phytoplankton in relation to water quality in Legedadi reservoir. Int J Ecol Environ Sci 15:1-16

Moffat B, Motlaleng GR, Thukuza A (2011a) Households willingness to pay for improved water quality and reliability of supply in Chobe ward, Maun. Botswana J Econ 8(12):45-61

Moffat B, Motlaleng GR, Thukuza A (2011b) Households willingness to pay for improved water quality and reliability of supply in Chobe ward, Maun. Botswana J Econ 8(12):45-61

Mogas J, Riera P, Bennett J (2006) A comparison of contingent valuation and choice modelling with second-order interactions. J For Econ 12(1):5-30

Molle F (2004) Defining water rights: by prescription or negotiation? Water Policy 6(3):207-227

MPR (2011). The Federal Democratic Republic of Ethiopia catchment rehabilitation and awareness creation for Geffersa, Legedadie, and Dire catchment areas, urban water supply and sanitation project report

Mulatu, N.D., (2013). Determinants of farmers' preference for adaptation strategies to climate change: evidence from north shoa zone of Amhara region Ethiopia. MPRA (Munich Personal RePEc Archive) Paper, (48753)

Negrín MA, Pinilla J, León CJ (2008) Willingness to pay for alternative policies for patients with Alzheimer's disease. Health Econ Policy Law 3(3):257-275
Null C, Kremer M, Miguel E, Hombrados JG, Meeks R and Zwane AP (2012) Willingness to pay for cleaner water in less developed countries: systematic review of experimental evidence. The International Initiative for Impact Evaluation (3iE)

Oliver, R.L., (2002). Value as excellence in the consumption experience. In Consumer value (pp. 59-78). Routledge

Özdemir S, Johnson FR, Hauber AB (2009) Hypothetical bias, cheap talk, and stated willingness to pay for health care. J Health Econ 28(4):894-901

Patterson, M. and Hardy, D., (2008). Economic drivers of change and their oceanic-coastal ecological impacts. Ecological economics of the oceans and coasts. Edward Elgar Publishing, pp.187-209

Pearce D (2002) An intellectual history of environmental economics. Annu Rev Energy Environ 27(1):57-81

Pearmain D, Kroes EP (1990) Stated preference techniques: a guide to practice

Petrin, A. and Train, K., (2003). Omitted product attributes in discrete choice models (no. w9452). National Bureau of economic research

Regier DA, Ryan M, Phimister E, Marra CA (2009) Bayesian and classical estimation of mixed logit: an application to genetic testing. J Health Econ 28(3):598-610

Rowcroft, P., Smith, S., Clarke, L., Thomson, K. and Reed, M., 2011. Barriers and opportunities to the use of payments for ecosystem services. Report to Defra

Sangkapitux C, Neef A, Polkongkaew W, Pramoon N, Nonkiti S, Nanthasen K (2009) Willingness of upstream and downstream resource managers to engage in compensation schemes for environmental services. Int J Commons 3(1)

Sanko, N., (2001). Guidelines for stated preference experiment design. Master of Business Adminstration diss., Ecole Nationale des Ponts et Chaussées. 5

Sattar, A., Ahmad, E. and Pant, K.P., (2007). Willingness to pay for the quality of drinking water [with comments]. The Pakistan Development Review.767-777

Sime I (1998) Addis Ababa water supply stage III-A project. Ethiopian Engineering Society, Addis Ababa, Ethiopia, p 13

Sonnier G, Ainslie A, Otter T (2007) Heterogeneity distributions of willingness-topay in choice models. Quant Mark Econ 5(3):313-331

Soto Montes de Oca G, Bateman IJ (2006) Scope sensitivity in households' willingness to pay for maintained and improved water supplies in Mexico City: investigating the influence of baseline supply quality and distribution upon stated preferences. Lincoln University, Commerce Division

TAHAL, SMEC, WWDSE, HyWAS (2005) Addis Ababa water supply project-stage IIA, final design report, volume II-1-pipe lines, distribution and transfer network

Tamene FD (2008) Assessment of lead toxicity awareness among battery charging garage and workshop workers and levels of lead in piped drinking water of Addis Ababa, Ethiopia. A thesis

Tanellari E, Bosch D, Boyle K, Mykerezi E (2015) On consumers' attitudes and willingness to pay for improved drinking water quality and infrastructure. Water Resour Res 51(1):47-57

Tarfasa S (2013) How much are households willing to contribute to the cost recovery of drinking water supply? Results from a household survey. Drink Water Eng Sci 6(1):33-38

Taye G, Poesen J, Wesemael BV, Vanmaercke M, Teka D, Deckers J, Goosse T, Maetens W, Nyssen J, Hallet V, Haregeweyn N (2013) Effects of land use, slope gradient, and soil and water conservation structures on runoff and soil loss in semi-arid northern Ethiopia. Phys Geogr 34(3):236-259

Tessema RA (2017) Assessment of the implementation of community-led total sanitation, hygiene, and associated factors in Diretiyara district, eastern Ethiopia. PLoS One 12(4):e0175233

Thiene M, Scarpa R (2009) Deriving and testing efficient estimates of WTP distributions in destination choice models. Environ Resource Econ 44(3):379

Thomson K, Kerle S, Waylenk K, Martin-Ortega J (2014) Water-based payment for ecosystem services (PES) schemes in Scotland

Train K, Weeks M (2005) Discrete choice models in preference space and willingness-to-pay space. In: Applications of simulation methods in environmental and resource economics. Springer, Dordrecht, pp 1-16

Train KE (2009) Discrete choice methods with simulation. Cambridge University Press

Twort AC, Law FM, Crowley FW and Ratnayaka DD (1994) Water supply (no. Ed. 4). Edward Arnold Ltd.

Um MJ, Kwak SJ, Kim TY (2002) Estimating willingness to pay for improved drinking water quality using averting behavior method with perception measure. Environ Resour Econ 21(3):285-300 
Van Bueren M, Bennett J (2004) Towards the development of a transferable set of value estimates for environmental attributes. Aust J Agric Resour Econ 48(1):1-32

Vásquez WF, Mozumder P, Hernández-Arce J, Berrens RP (2009) Willingness to pay for safe drinking water: evidence from Parral, Mexico. J Environ Manag 90(11):3391-3400

Vuletić D, Benko M, Dubravac T, Krajter S, Novotny V, Indir K, Balenović I (2009) Review of nonmarket forest goods and services evaluation methods. Period Biol 111(4):515-521

Wang H, Xie J, Li H (2010) Water pricing with household surveys: a study of acceptability and willingness to pay in Chongqing, China. China Econ Rev 21(1):136-149

WaterAid (2017) The recipe for success: how policymakers can integrate water, sanitation and hygiene into actions to end malnutrition

Watkins K (2006) Human development report 2006-beyond scarcity: power, poverty and the global water crisis

Welle K, Schaefer F, Butterworth J, Bostoen K (2012) Enabling or disabling? Reflections on the Ethiopian national WASH inventory process. IDS Bull 43(2):44-50

Windle J, Rolfe J (2013) Estimating nonmarket values of Brisbane (state capital) residents for state based beach recreation. Ocean Coast Manag 85:103-111

Witzke M, Rumbach P, Go DB, Sankaran RM (2012) Evidence for the electrolysis of water by atmospheric-pressure plasmas formed at the surface of aqueous solutions. J Phys D: Appl Phys 45(44):442001

World Bank (1996) African water resources: challenges and opportunities for sustainable development: World Bank technical paper no. 331, African WATER SCARCITY AND URBAN AFRICA 647 technical department series. World Bank, Washington, DC

WWAP, U. (2015) The United Nations world water development report 2015: water for a sustainable world. United Nations World Water Assessment Programme

Xiong K, Kong F, Zhang N, Lei N, Sun C (2018) Analysis of the factors influencing willingness to pay and payout level for ecological environment improvement of the Ganjiang River basin. Sustainability 10(7):2149

\section{Submit your manuscript to a SpringerOpen ${ }^{\circ}$ journal and benefit from:}

- Convenient online submission

- Rigorous peer review

- Open access: articles freely available online

- High visibility within the field

- Retaining the copyright to your article

Submit your next manuscript at $\boldsymbol{\nabla}$ springeropen.com 